\title{
Retrodeformation as a test for the validity of phylogenetic characters: an example from diplodocid sauropod vertebrae
}

\author{
Emanuel Tschopp, João Russo, and Gordon Dzemski
}

\begin{abstract}
Tectonic strain is ubiquitous in rock formations, leading to deformations, faults, and cracks at small as well as large scales. Fossils embedded in these strata will passively participate in these deformations, and have rarely been found undistorted. This affects ratios used in phylogenetic analyses. As a case study, diplodocid (Dinosauria: Sauropoda) cervical vertebrae were subjected to two different methods of retrodeformation, and the same methods were tested with a manually deformed digital model of a Dodo (Raphus cucullatus, Linnaeus, 1758) cervical vertebra. The results indicate that shape changes considerably in all dimensions. The tests showed that generally, retrodeformation restored symmetry, but increased deformation induced by compression. By comparing the trends obtained by the Raphus cucullatus analysis with the results from the diplodocid vertebrae, phylogenetic characters that are more prone to various types of deformations were identified. Phylogenetic analyses without these questionable characters generally yielded better resolution, shorter most parsimonious trees, and higher supporting values. Ratios used for character definitions, as well as other character information possibly affected by deformation, have to be applied very carefully, and highly susceptible ratios should be avoided a priori. As shown in this study, retrodeformation can work as a tool to identify such ratios and characters, but it has to be simultaneously tested with similar bones from extant taxa.
\end{abstract}

Emanuel Tschopp. Universidade Nova de Lisboa, Faculdade de Ciências e Tecnologia-CICEGe, Monte de Caparica, Portugal and Museu da Lourinhã, Rua João Luis de Moura, 2530-158 Lourinhã, Portugal.

tschopp.e@campus.fct.unl.pt

João Russo. Museu da Lourinhã, Rua João Luis de Moura, 2530-158 Lourinhã, Portugal.

jpvmrusso@gmail.com

Gordon Dzemski. Institut für Biologie und Ihre Didaktik, Universität Flensburg, Germany. dzemski@uniflensburg.de

Keywords:Deformation; Sauropoda; phylogeny; digital models; cervical vertebrae 


\section{INTRODUCTION}

During the process of preservation, biological hard tissues usually undergo a certain amount of taphonomic deformation that can induce a loss of biologically important information (Hughes and Jell, 1992; Dunlavey et al., 2004; Angielczyk and Sheets, 2007; Boyd and Motani, 2008; Arbour and Currie, 2012). Quantifying the amount of distortion is crucial for studies of taxonomy, ontogeny, or biomechanics of these organisms, and numerous studies proposed different methods of how to achieve that aim (e.g., Sdzuy, 1966; Cooper, 1990; Williams, 1990; Hughes and Jell, 1992; Rushton and Smith, 1993; Motani, 1997; Ponce de León and Zollikofer, 1999; Zollikofer and Ponce de León, 2005; Ogihara et al., 2006; Srivastava and Shah, 2006; Angielczyk and Sheets, 2007; Gunz et al., 2009; Kazhdan et al., 2009; Arbour and Currie, 2012; Molnar et al., 2012). The various approaches were categorized under the term retrodeformation by Williams (1990), implying that they deform the fossil another time, but in the reverse direction, ideally recovering the original undeformed shape (Ponce de León and Zollikofer, 1999). Most of these techniques focused on the reconstruction of the original shape of two-dimensional images of rather simply shaped invertebrates (e.g., Cooper, 1990; Rushton and Smith, 1993), or on the calculation of strains in the matrix preserving the fossils (e.g., Sdzuy, 1966; Srivastava and Shah, 2006). In certain cases, retrodeformation methods resulted in considerable systematic changes, enabling the researchers to unite various taxa that were previously distinguished based on distorted length ratios (Hughes and Jell, 1992; Motani, 1997). In more complexly shaped, three-dimensionally preserved fossils, the probability that different parts are deformed in non-uniform ways is higher. Furthermore, since tectonic events rarely deform rocks in a homogeneous way, fossils with high relief or varying mechanical properties from the matrix are particularly susceptible to plastic as well as brittle deformation (Hughes and Jell, 1992; Boyd and Motani, 2008). Whereas the former changes the shape of the fossil without breaking it, the latter fractures the object and displaces the parts relative to each other (Zollikofer and Ponce de León, 2005; Boyd and Motani, 2008; Arbour and Currie, 2012). Some of the increasing number of attempts to reconstruct the original shape of three-dimensional fossils were made with plesiosaur cervical vertebrae (Motani et al., 2005), a skull of a snake (Polcyn et al., 2005), a vertebra of an early tetrapod (Molnar et al., 2012), and most importantly, primate skulls (e.g., Ponce de León and Zollikofer, 1999; Zollikofer et al., 2005, 2009; Zollikofer and Ponce de León, 2005; Ogihara et al., 2006; Gunz et al., 2009). Recently, retrodeformation was also shown to be useful to detect areas with high probabilities of being deformed, thereby allowing to validate taxonomic affinities (Arbour and Currie, 2012).

Sauropod, and particularly diplodocid cervical vertebrae exhibit extremely complex structures with numerous laminae and cavities (Wilson, 1999). Vertebral morphology thus contributes a large part of phylogenetic analyses of sauropods (e.g., Wilson, 2002; Upchurch et al., 2004). However, since such complex structures are more susceptible to deformation, information obtained from distorted elements has to be interpreted with special care. In the present case study, 3D models of the holotype neck of the diplodocid sauropod Kaatedocus siberi Tschopp \& Mateus, 2012 were subjected to two different retrodeformation tools provided within the geometric morphometrics software Landmark ${ }^{\mathrm{TM}}$ (Motani et al., 2005; Wiley et al., 2005: www.idav.ucdavis.edu/research/EvoMorph). These tools address plastic deformation based on bilaterally symmetric points on the surface of the element, in order to reconstruct its initial shape. In order to evaluate the results, the same methods were applied to a digitally deformed 3D model of a cervical vertebra of Raphus cucullatus (Aves, Columbiformes) allowing identification of phylogenetic characters that are based on ratios highly susceptible to deformation processes.

Abbreviations. CV: cervical vertebra; DNSM: Durban Natural Science Museum, South Africa; MM: Motani Method; SAM: Single Axis Method; SMA: Sauriermuseum Aathal, Switzerland.

\section{MATERIAL AND METHODS}

This case study is based on the articulated neck of the holotype of Kaatedocus siberi (SMA 0004; Tschopp and Mateus, in press) found at Howe Quarry close to Shell in north-central Wyoming. The site lies in the Upper Jurassic Morrison Formation, and the vertebrae were subject to both plastic and brittle deformation (Figure 1). The specimen was scanned in 3D using a structured light scanner (Tschopp and Dzemski, 2012). The obtained digital models were imported into Landmark $^{\text {TM }}$ (Motani et al., 2005; Wiley et al., 2005: www.idav.ucdavis.edu/research/EvoMorph), a program facilitating the placing of landmarks on threedimensional surfaces for geometric morphometric analyses, as well as providing tools for retrodefor- 


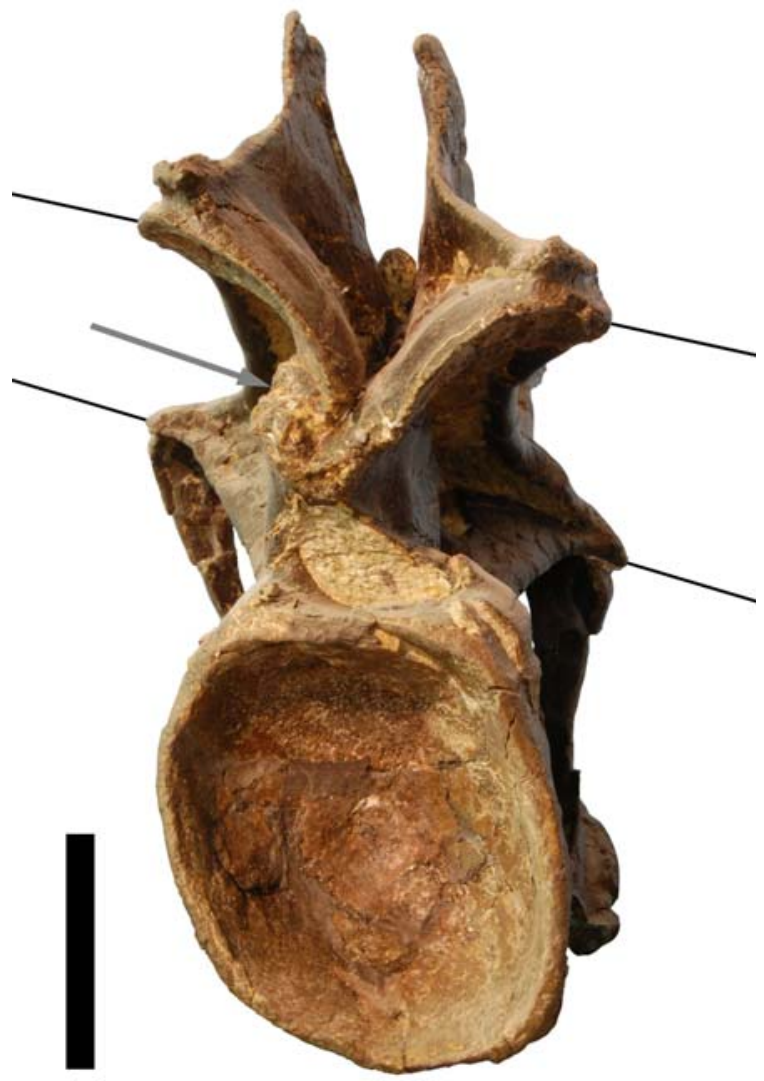

FIGURE 1. Posterior view of CV 12 showing brittle (arrow) and plastic deformation (lines; indicate the originally horizontal plane of postzygapophyses (above) and transverse processes (below)). Scale bar equals $5 \mathrm{~cm}$.

mation of distorted specimens. The retrodeformation tools offer two methods called Single Axis (SAM) and Motani Method (MM), and are both based on bilateral symmetry. The SAM assumes that the object under study was compressed during fossilization, and that this compression took place in a single axis (for detailed mathematical backgrounds see Kazhdan et al., 2009), a hypothesis which has also been used by Zollikofer and Ponce de León (2005). Since no additional information is given or referred to concerning the MM (only an abstract mentioning it: Motani et al., 2005), interested readers are further referred herein to an earlier publication on retrodeformation of 2D photographs of distorted fossils by Motani (1997), which is mainly based on two assumptions: homogenous/linear deformation within the study area, and that the undeformed shape of vertebral centra is cylindrical (Motani, 1997; Motani et al., 2005).

In order to apply these methods, 16 bilaterally symmetric landmark pairs were chosen on the ver- tebrae (Figure 2). Retrodeformed models were produced using SAM and MM for the cervical vertebrae 3 to 14, and will herein be called SAM16 , or MM-16 models respectively. In order to further analyze the methods behind the tools, obtained retrodeformed models of $\mathrm{CV} 12$ were subjected to a second iteration with the respective method (hereinafter called 2xSAM or 2xMM), and restored models of CV 12 were produced using different numbers of defining landmarks (four and nine pairs; herein called SAM-4 and MM-4, or SAM-9 and MM-9, respectively).

Comparisons were conducted using 2D imaging software: pictures of corresponding views of original and retrodeformed models were stacked and certain landmarks as well as the outline traced in order to visualize induced shape changes (Figures 3,4$)$. The retrodeformed models of $\mathrm{CV} 14$ were also imported into LightWave 3D ${ }^{\mathrm{TM}}$ (NewTek). Videos of CV 14 in right lateral, dorsal, and posterior view were rendered by changing transparency between the original and the retrodeformed models, to highlight occurred shape changes (Appendices $1,2,3$ ).

In order to evaluate the applied retrodeformation tools, the same methods as above described were used on a manually deformed 3D model of a cervical vertebra of a Dodo (Raphus cucullatus, Linnaeus 1758; DNSM Ornithology 2366). The original model was generously provided by Aves 3D (www.aves3D.org) and the DNSM. In order to deform the model, two modifying tools in LightWave Modeler® were used, based on the deformation of the vertebrae of SMA 0004 . Three different deformed models of the Raphus cucullatus vertebra were produced by applying shear, compression, as well as shear and compression combined (already implemented tools in the LightWave Modeler, compression can be introduced by using the stretch tool). For the combination of both, shearing was applied before compression. The amount of deformation was chosen trying to mimic the deformed diplodocid vertebrae.

Five ratios used to define numerical characters describing cervical vertebra shape in three different phylogenetic analyses (Upchurch et al., 2004; Harris, 2006; Whitlock, 2011) were tested for their susceptibility to changes during taphonomic deformation and automated retrodeformation. The ratios of the original model of Raphus cucullatus were compared to the respective ratios obtained from both the deformed and retrodeformed models, in order to identify questionable characters. The trends recovered in the Raphus cucullatus test 


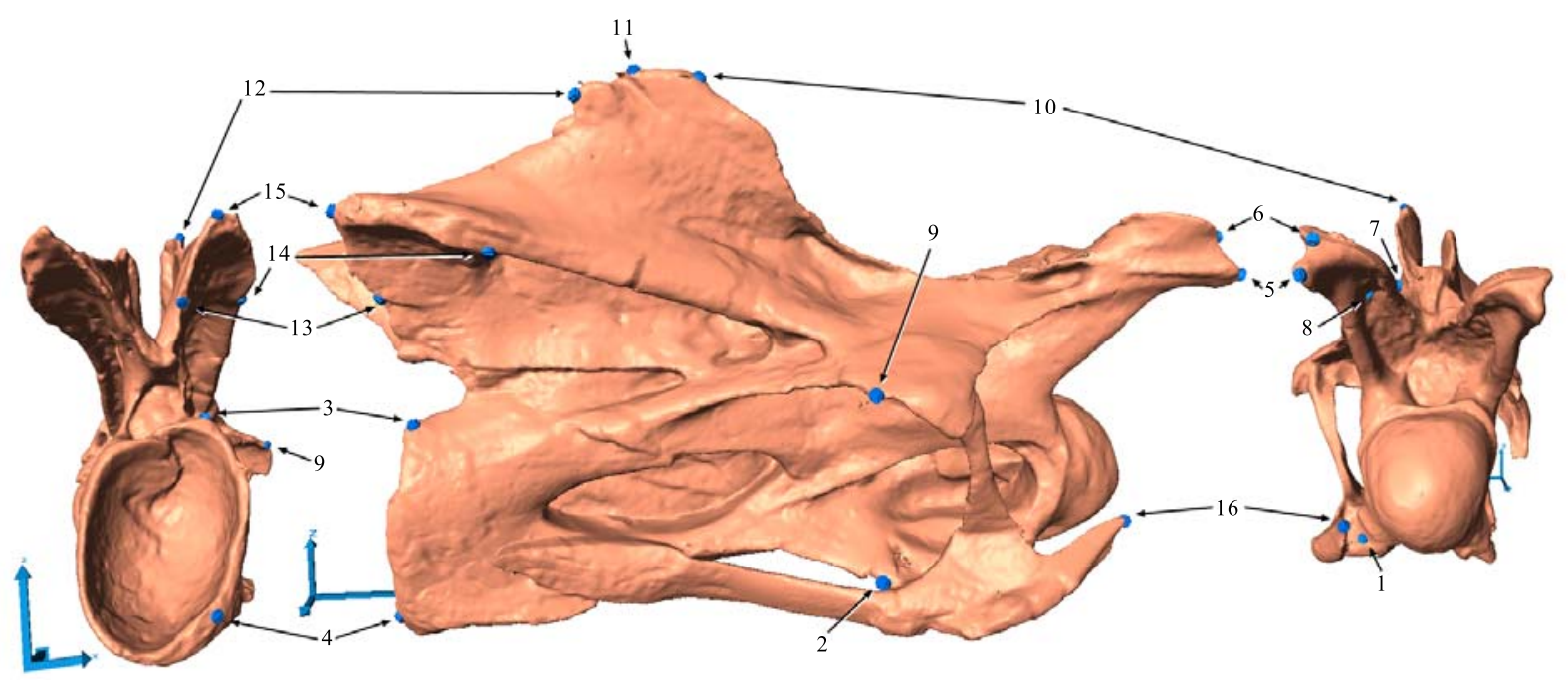

FIGURE 2. Landmarks used for the retrodeformation methods, shown in CV 10 in posterior, right lateral, and anterior view (from left to right). Only landmarks on right side are shown. The landmarks on the centrum are: 1) anteromedial corners of the parapophyses; 2) posterior ends of the parapophyses; 3 ) dorsolateral corner of the border of the cotyle, where the centropostzygapophyseal laminae converge with the centrum; 4) ventrolateral corner of the cotyle, where the posterolateral flanges of the ventral surface of the centrum merge with the border of the cotyle. The landmarks on the neural arch are: 5) anterior ends of prezygadiapophyseal laminae; 6) anterior-most points of prezygapophyses; 7) medial-most point of prezygapophyses; 8) medial sides of insertion of centroprezygapophyseal laminae into prezygapophyses; 9) posterolateral-most points of transverse processes; 10) anterior-most points of the neural spine summit; 11) small protrusions at the center of the neural spine summit; 12) posterior-most point of the neural spine summit; 13) posteromedial corners of postzygapophyses; 14) anterolateral corners of postzygapophyses; 15) posterior ends of spinopostzygapophyseal laminae. The landmark on the cervical rib is its anterior-most tip (16).

were compared to the trends seen in the diplodocid analysis, resulting in the identification of possibly inverted shape changes relative to the true, but in this case unknown, original form. Two characters were identified as questionable $(\mathrm{H} 112$ and $\mathrm{H} 114$, which is basically the same as W90; Tables 1,2). For both datasets (Harris, 2006; Whitlock, 2011), two phylogenetic analyses were performed with and without the questionable characters, using WinClada (version 1.00.08; www.cladistics.com), and the results, as well as the tree length, bootstrap values, consistency index, and retention index of the recovered strict consensus trees were compared (Table 3).

\section{RESULTS}

\section{Retrodeformation}

General Morphological Changes (SAM-16; MM16). Retrodeformed models obtained by application of the SAM are much more bilaterally symmetrical than both the original fossil and the MM-16 models. Landmarks are brought to almost the same horizontal and vertical level after applying SAM-16, whereas MM-16 usually yielded interme- diate results between the original bones and the SAM-16 models (Figures 5, 6, 7, 8, 9). SAM-16 reconstructions are generally shorter, broader transversely, and at least as high as the original version. The direction of the induced shape changes (more gracile vs. more robust) by the MM appears to be more variable (Table 1): MM-16 of CV 10, for example, produced a more slender reconstruction compared to the original element (Figure 5). Condyle and cotyle outlines become more rounded with both methods (Figures 5, 6, 7, 8, 9).

Application of Second Iteration (2xSAM; 2xMM). Whereas a second iteration of SAM did not affect the results, shape changes considerably between MM-16 and 2xMM models. With 2xMM, symmetry was slightly more restored, although still not to the degree as in the SAM-16 models. Unexpectedly, in the case of CV 12, where the first step yielded a more robust model, the 2xMM model inverted this trend, producing a reconstruction even more slender than the original fossil (Figure $3)$.

Use of Different Numbers of Landmark Pairs (SAM-4, -9, -16; MM-4, -9, -16). Using different 

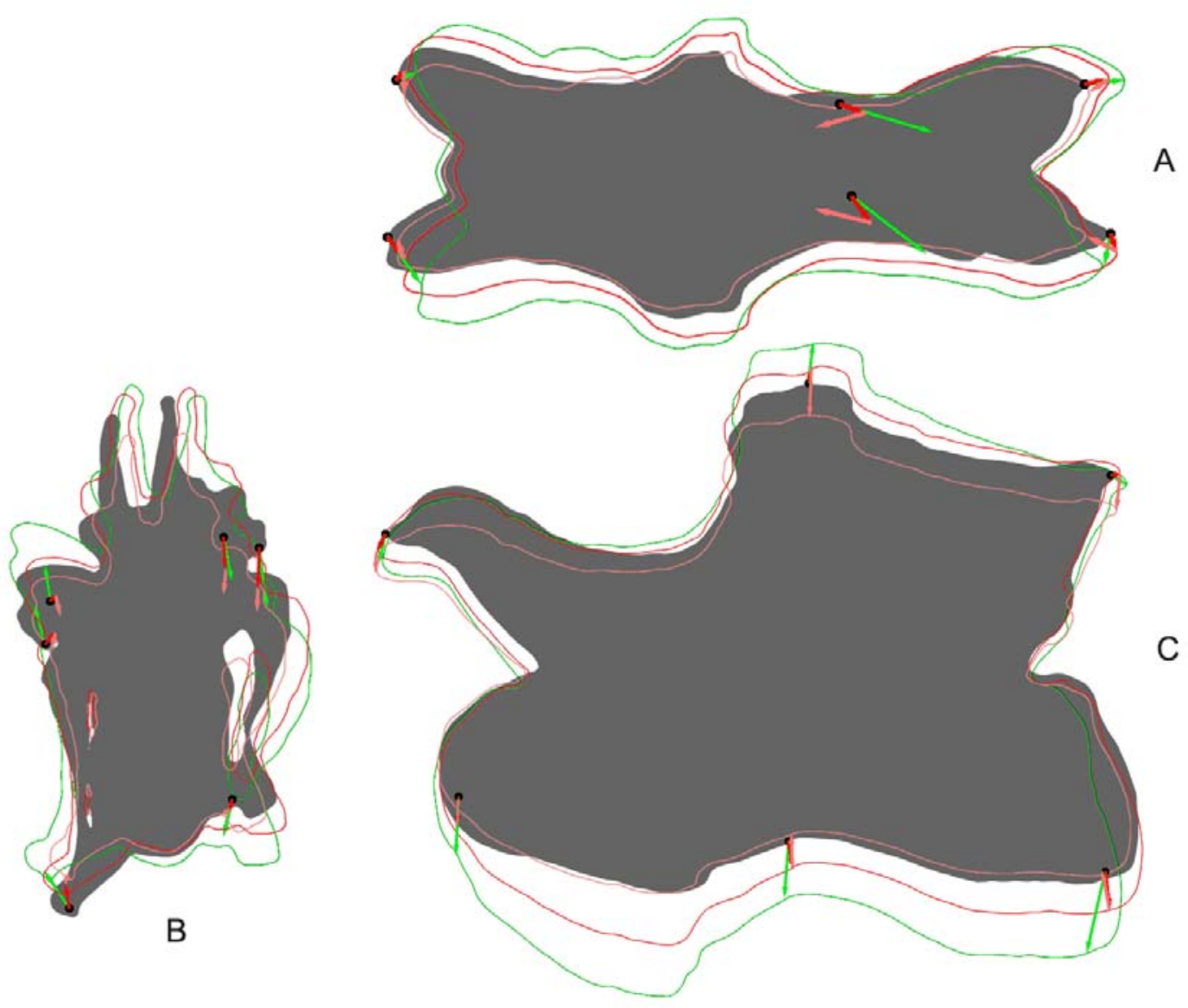

FIGURE 3. Shape changes after two retrodeformation steps in CV 12 in dorsal (A), anterior (B), and left lateral (C) view. The full shape marks the original deformed model, the outlines show the shape of the retrodeformed models (green: SAM, dark and light red: MM, two steps).

numbers of defining landmarks showed very few differences between the obtained models when applying the SAM. On the other hand, MM-9 and MM-16 models are much more similar to each other than to the MM-4 models. They are shorter and more slender than MM-4 models, which are relatively robust with a pronounced posteroventral corner of the vertebral centrum and an elevated neural spine summit (Figure 4).

Test with the Raphus cucullatus cervical vertebra. The retrodeformed models of Raphus cucullatus generally compared very badly with the original bone. Whereas overall symmetry was restored to a large degree during the retrodeformation process, the same cannot be said for the proportions (Figures 10, 11, 12; Table 2). The only retrodeformed model that matched the original state more than the respective deformed model was MM-16 applied to the transversely compressed vertebra - mainly due to the disproportionately elongated postero- ventral edge of the centrum (Table 2). Both methods thus appear very weak in coping with shear, which is the most evident deformation present in Kaatedocus SMA 0004.

Analyzing the implied shape changes, it becomes evident that the more dimensions are involved in taking the measurements, the more these ratios are prone to deformation (Table 2). Height of the neural arch to height of the posterior articular surface of the centrum (character H115), for example, can be measured on one single line, and the majority of the changes introduced by deformation and retrodeformation are below $5 \%$. On the other hand, height to width of the posterior articular surface (character $\mathrm{H} 112$ ), has to be measured in a plane, and shape changes considerably.

Comparing the recovered trends from the Raphus cucullatus test with the trends obtained by retrodeforming the Kaatedocus vertebrae reveals that they are inverted in many cases (Table 1). As 

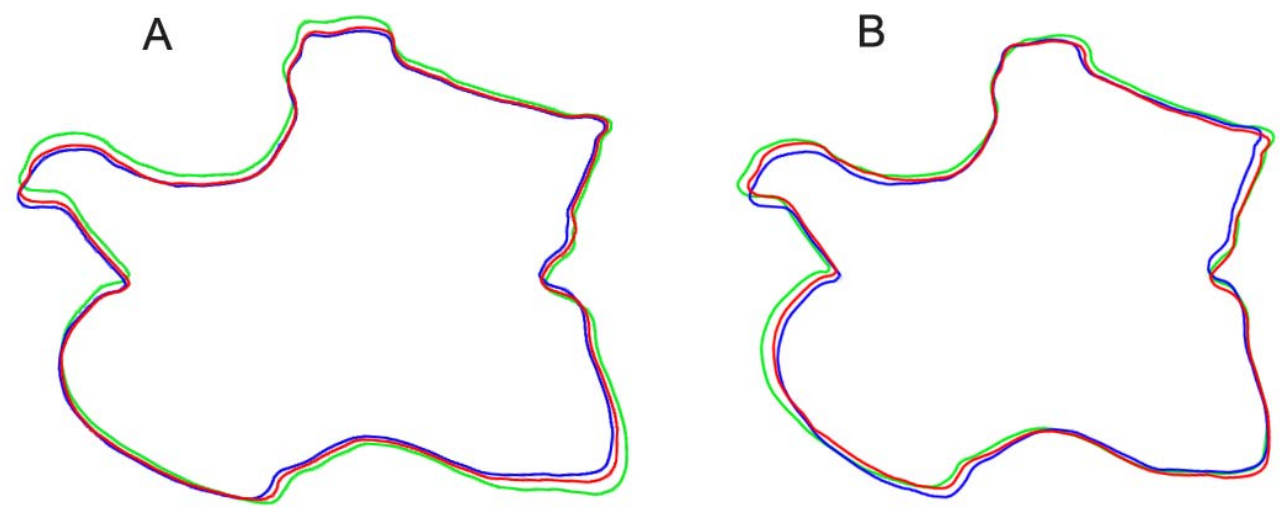

FIGURE 4. Outlines of different retrodeformed models of CV 12 obtained by using 4 (green), 9 (blue), or 16 (red) landmarks to define the midsagittal plane. A: results of the MM, B: results of the SAM.

the deformation introduced to the Raphus cucullatus model was chosen to mimic taphonomic distortion of the SMA 0004 elements, a comparison of the recovered trends allows validation of the retrodeformation of the diplodocid vertebrae. Given this, it appears that depending on the ratios, both SAM16 and MM-16 can recover real trends, but the true dimensions still remain impossible to determine. Based on these comparisons, the following characters were identified as questionable: H112, because of a very high susceptibility to deformation, and ambiguity in the trends of retrodeformation; and H114 (or W90), due to relatively bad results in the test, and false trends and/or intermediate, inapplicable ratios of the retrodeformed models of SMA 0004 (Tables 1, 2).

\section{Phylogeny}

Phylogenetic analyses usually contain a mix of qualitative and quantitative characters as retrodeformation and thus deformation sometimes considerably change dimensions, especially scores for numerical characters can be affected. The two analyzes performed (using matrices of Harris, 2006, and Whitlock, 2011) yielded slightly varying tree topologies when including or excluding the previously identified questionable characters. Using Harris (2006), without the questionable characters, resolution of the tree increases, tree length of the strict consensus tree decreases considerably, and consistency and retention indexes are slightly higher. Bootstrap values are higher for high-level taxa like Neosauropoda, Titanosauriformes, and Diplodocoidea, whereas lower level taxa have lower support when excluding the questionable characters (Figure 13, Table 3). Perform- ing the analysis of Whitlock (2011), the differences are smaller, but the same trends are observable: a shorter tree, higher consistency index (Table 3), as well as generally higher bootstrap values for highlevel taxa (in this case: Jobaria + Neosauropoda, Flagellicaudata, Dicraeosauridae, and Diplodocidae; Figure 14). The diplodocine intrarelationships are different in the two analyses based on Whitlock (2011), but bootstrap values are less than $50 \%$ in both recovered trees, indicating that more thorough taxonomic research is needed within this clade.

\section{DISCUSSION}

\section{Retrodeformation}

One of the basic problems of the reconstruction of deformed fossils is the fact that the original undeformed shape of the elements is unknown. Therefore, any retrodeformation technique has to rely on certain assumptions. The vast majority of these methods (including SAM and MM) assume that the objects under study are bilaterally symmetrical. Problematic issues concerning retrodeformation thus include asymmetrical elements or symmetrical deformation like compression. Partly due to this, automated retrodeformation sometimes even yields models that are less similar to the original shape than the deformed elements, as shown by Angielczyk and Sheets (2007), as well as the Raphus cucullatus test in this study.

The methods employed here require at least four pairs of bilaterally symmetric landmarks for the calculation of the midsagittal plane. However, the calculated plane, on which the retrodeformation is based, often does not pass through landmarks like the median tuberosity in the middle of the bifurcate 
TABLE 1. Numerical characters used in phylogenetical analyses, with the corresponding ratios of the original vertebrae of the Kaatedocus siberi SMA 0004, the MM models, and the SAM models. Trends recovered by retrodeformation are compared to the Raphus cucullatus test, green indicates probable real trends for SMA 0004 . Abb.: H112, character 112 of Harris (2006); U1, character 1 of Upchurch et al. (2004); W87, character 87 of Whitlock (2011).

\begin{tabular}{|c|c|c|c|c|c|c|c|c|}
\hline \multirow{2}{*}{ Character } & \multirow{2}{*}{$\begin{array}{l}\text { Borders as set in } \\
\text { character }\end{array}$} & \multirow{2}{*}{ Vertebra } & \multirow{2}{*}{ Original } & \multicolumn{2}{|c|}{ Retrodeformed } & \multicolumn{2}{|c|}{ Comparison with trends } & \multirow{2}{*}{ Comments } \\
\hline & & & & MM & SAM & MM & SAM & \\
\hline
\end{tabular}

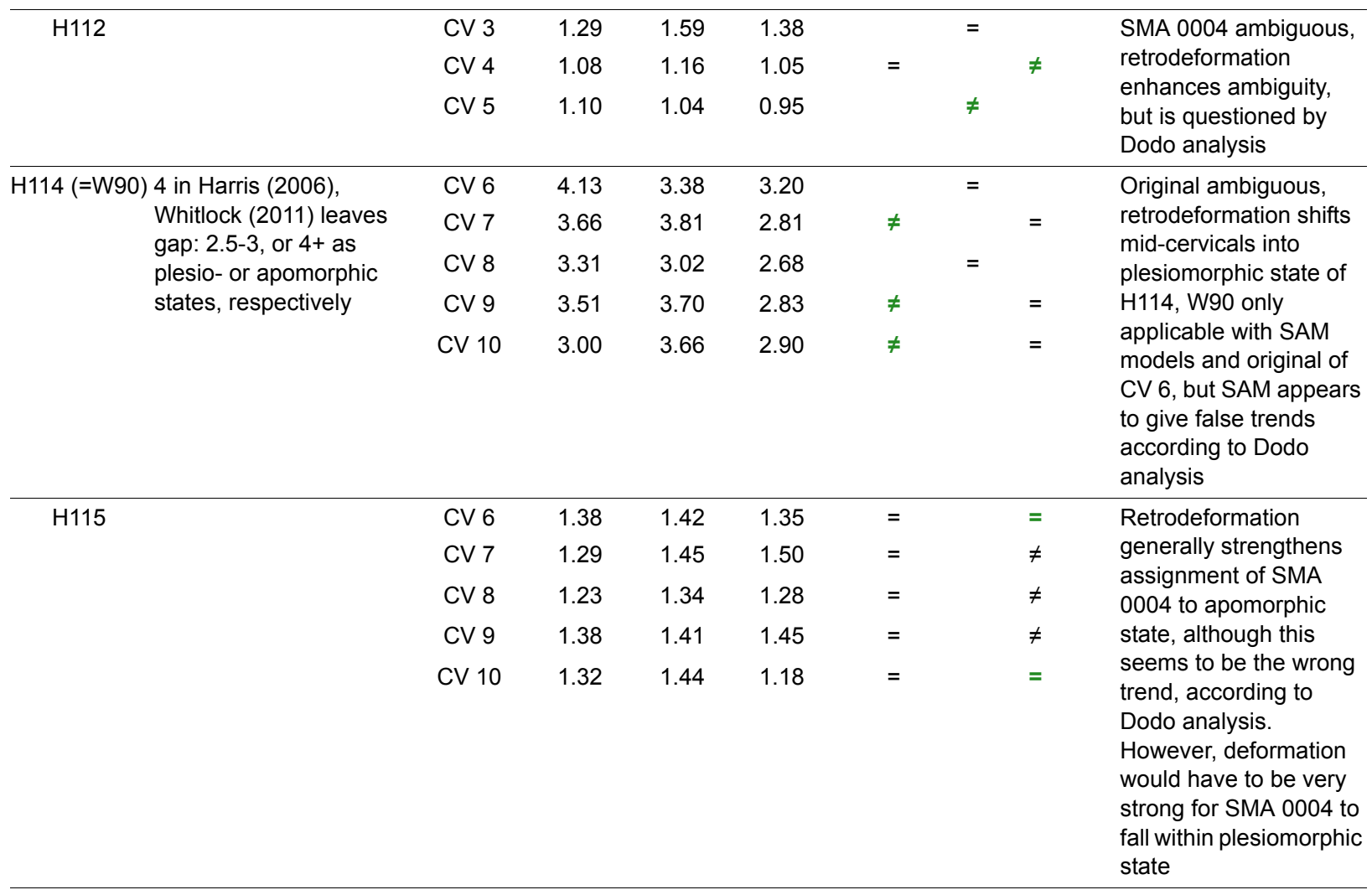

neural spines (Figure 15). The number of constraining points in the methods included into Landmark $^{\mathrm{TM}}$, and thereby also the quality of the retrodeformation process, could be considerably augmented by including single landmarks on the sagittal plane, as implemented in the method of Ogihara et al. (2006).

Our results obtained by defining a varying number of landmark pairs do not confirm that the more landmarks you define to constrain the plane of symmetry, the more accurate the outcome (Motani et al., 2005; Ogihara et al., 2006; Gunz et al., 2009). In fact, where differences are visible (using MM), models obtained by MM-9 and MM-16 are more slender, and tightly reproduce the false trends recovered by the Raphus cucullatus test. The method in itself thus appears to be more thorough and consistent when using more landmark pairs, but one has to pay attention to not take this as an indication for higher accuracy of the retrodeformation. The fact that a second application of the MM to an already retrodeformed object often changes its shape in almost opposing directions sheds additional doubts on the validity of the MM. In order to verify this accuracy, a test of the method has to be performed with manually deformed, morphologically similar elements, mimicking as closely as possible the taphonomy of the study objects.

Unexpectedly, the trends recovered by the diplodocid case study and the Raphus cucullatus test are often opposite to each other (Tables 1, 2). This is surprising, especially since bird vertebrae are the most similar in morphology you can get to sauropod vertebrae within extant animals, and also because digital deformation of the Raphus cucullatus vertebra was designed to mimic as closely as possible the taphonomic processes that affected SMA 0004. Two possible explanations are imagin- 
TABLE 1 (continued).

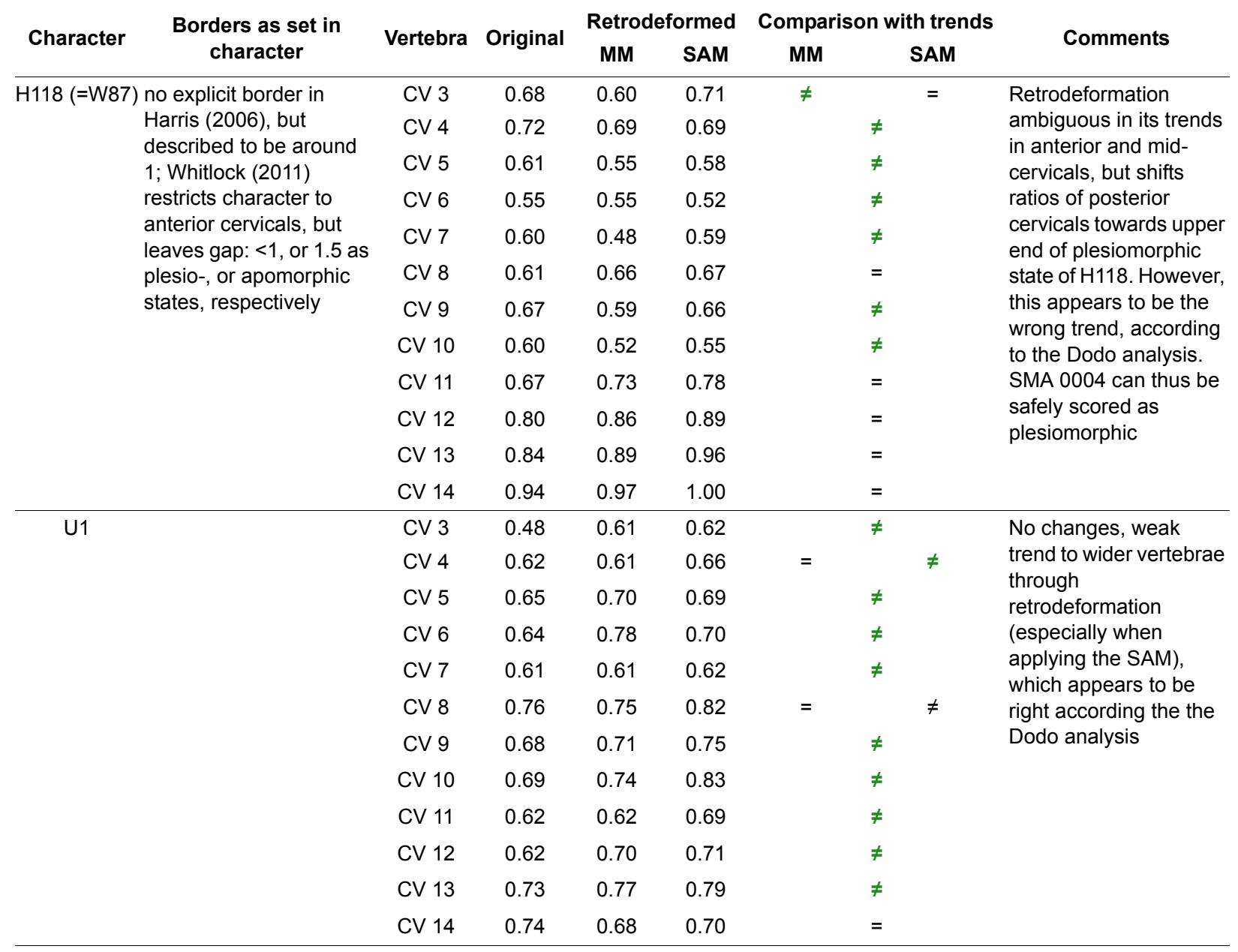

able: first, it is conceivable that different algorithms in automated retrodeformation tools yield differing, but still bilaterally symmetrical models. However, applying the methods with the same default settings to all elements under study, it would be odd if they would produce opposite trends. Second, it could be that the varying trends are due to the additional brittle deformation in SMA 0004, which was not attempted to reproduce in the manually deformed Raphus cucullatus vertebra. In order to cope with brittle deformation, previous researchers disassembled and retrodeformed single parts independently, before applying automated retrodeformation tools to the reassembled object. To our knowledge, this procedure has only been performed with hominoid skulls (e.g., Zollikofer et al., 1998, 2005; Ponce de León and Zollikofer, 1999; Ogihara et al., 2006; Gunz et al., 2009), which are often the only elements recovered from the entire skeleton. Whereas such complex and time-consuming reconstructions are justifiable in such cases, they are hardly appropriate for large numbers of elements as the 15 cervical vertebrae in diplodocid sauropod necks as considered here. However, since methodological errors can most probably be excluded as reasons for the differing trends, retrodeformation can be used to test the validity of length ratios, and thus the usefulness of morphological characters used in phylogenetic analyses.

\section{Phylogeny}

The higher resolution and support values of the recovered phylogenetic trees, when excluding the questionable characters, imply that deformation negatively affects the accuracy of phylogenetic analyses. However, the fact that bootstrap values for lower-level taxa appear to decrease considerably in some cases (e.g., Diplodocinae, Figures 13, 14 ), indicates that these questionable characters might still be phylogenetically informative at lower taxonomical levels. The question then rises if it 
TABLE 2. Numerical characters used in phylogenetic analyses, with the corresponding ratios of the original vertebra of Raphus cucullatus, the deformed models, the MM models, and the SAM models. The closest fit with the original vertebra is marked with bold numbers. Differences between the deformed/retrodeformed models and the original are given in percent, with high deviations ( $>50 \%$ ) marked in red, and low differences $(<5 \%)$ in green. The similarity of the retrodeformed models with the original vertebra is given compared with the deviance of the deformed model (arrows pointing upwards indicate a closer fit between retrodeformed models and original vertebra, arrows pointing down show that the retrodeformation increased deformation even more; two arrows show higher (green) or lower (red) accuracy of the respective retrodeformation method compared with the other one). Abb.: H112, character 112 of Harris (2006); U1, character 1 of Upchurch et al. (2004); W87, character 87 of Whitlock (2011).

\begin{tabular}{|c|c|c|c|c|c|c|c|c|c|}
\hline \multirow{5}{*}{$\begin{array}{c}\text { Character } \\
\mathrm{H} 112\end{array}$} & \multirow{4}{*}{$\begin{array}{l}\text { Character definitions } \\
\text { Height/width posterior } \\
\text { articular surface }\end{array}$} & \multirow{4}{*}{$\begin{array}{c}\begin{array}{c}\text { Undeformed } \\
\text { original }\end{array} \\
0.61\end{array}$} & \multirow{2}{*}{\multicolumn{2}{|c|}{$\begin{array}{l}\text { Deformed } \\
\text { models }\end{array}$}} & \multicolumn{2}{|c|}{ Retrodeformed } & \multicolumn{3}{|c|}{ Difference from undeformed } \\
\hline & & & & & \multirow{2}{*}{$\begin{array}{l}\text { MM } \\
1.30\end{array}$} & \multirow{2}{*}{$\begin{array}{c}\text { SAM } \\
1.28\end{array}$} & \multirow{2}{*}{$\begin{array}{c}\text { deformed } \\
210.20 \%\end{array}$} & \multirow{2}{*}{$\begin{array}{c}\text { MM } \\
215.09 \%\end{array}$} & \multirow{2}{*}{$\begin{array}{c}\text { SAM } \\
211.25 \%\end{array}$} \\
\hline & & & $\mathrm{C}$ & 1.27 & & & & & \\
\hline & & & $S$ & 0.84 & 0.75 & 0.69 & $139.25 \%$ & $124.65 \%$ & $114.11 \%$ \\
\hline & & & CS & 1.16 & 1.18 & 1.18 & $190.85 \%$ & $194.52 \%$ & $195.19 \%$ \\
\hline \multirow[t]{3}{*}{ H114 (=W90) } & \multirow{3}{*}{$\begin{array}{l}\text { Centrum length/height } \\
\text { of posterior articular } \\
\text { surface }\end{array}$} & 2.00 & C & 1.45 & 1.63 & 1.45 & $72.32 \%$ & $81.25 \%$ & $72.73 \%$ \\
\hline & & & $S$ & 2.09 & 2.33 & 2.38 & $104.65 \%$ & $116.67 \%$ & $119.23 \%$ \\
\hline & & & CS & 1.44 & 1.23 & 1.20 & $72.00 \%$ & $61.32 \%$ & $59.80 \%$ \\
\hline \multirow[t]{3}{*}{$\mathrm{H} 115$} & \multirow{3}{*}{$\begin{array}{l}\text { Height neural arch/ } \\
\text { height of posterior } \\
\text { articular surface }\end{array}$} & 1.33 & $\mathrm{C}$ & 1.36 & 1.18 & 1.29 & $102.48 \%$ & $88.91 \%$ & $97.38 \%$ \\
\hline & & & $S$ & 1.33 & 1.31 & 1.34 & $100.00 \%$ & $98.65 \%$ & $101.25 \%$ \\
\hline & & & CS & 1.42 & 1.43 & 1.40 & $107.35 \%$ & $108.18 \%$ & $105.90 \%$ \\
\hline \multirow[t]{3}{*}{ H118 (=W87) } & \multirow{3}{*}{$\begin{array}{l}\text { Total height/centrum } \\
\text { length }\end{array}$} & 1.47 & $\mathrm{C}$ & 1.76 & 1.47 & 1.75 & $119.57 \%$ & $100.18 \%$ & $119.06 \%$ \\
\hline & & & $S$ & 1.28 & 1.16 & 1.23 & $86.93 \%$ & $79.13 \%$ & $83.40 \%$ \\
\hline & & & CS & 2.05 & 2.22 & 2.37 & $139.52 \%$ & $151.18 \%$ & $160.92 \%$ \\
\hline \multirow[t]{3}{*}{ U1 } & Total width/total height & 1.31 & $\mathrm{C}$ & 0.87 & 0.94 & 0.91 & $66.17 \%$ & $71.50 \%$ & $68.96 \%$ \\
\hline & & & $S$ & 1.38 & 1.49 & 1.57 & $104.97 \%$ & $113.84 \%$ & $119.73 \%$ \\
\hline & & & CS & 0.97 & 0.92 & 0.89 & $73.67 \%$ & $69.89 \%$ & $68.14 \%$ \\
\hline
\end{tabular}

TABLE 2 (continued).

\begin{tabular}{|c|c|c|c|c|}
\hline \multirow{2}{*}{ Character } & \multirow[b]{2}{*}{ Comments on character } & \multicolumn{2}{|c|}{ Retrodeformation trends } & \multirow{2}{*}{ Comments on retrodeformation } \\
\hline & & MM & SAM & \\
\hline \multirow[t]{3}{*}{$\mathrm{H} 112$} & \multirow[t]{3}{*}{ highly susceptible, should be deleted } & $\searrow \searrow$ & $У$ & \multirow{3}{*}{$\begin{array}{l}\text { increases transverse compression even } \\
\text { more, both MM and SAM indicate trend if } \\
\text { shear only }\end{array}$} \\
\hline & & ス & スス & \\
\hline & & $\searrow$ & $y$ & \\
\hline \multirow[t]{3}{*}{ H114 (=W90) } & \multirow[t]{3}{*}{ susceptible, use with care } & ス & - & \multirow{3}{*}{$\begin{array}{l}\text { bad performance if shear involved, MM } \\
\text { indicates trend if compression only }\end{array}$} \\
\hline & & $y$ & $\searrow \searrow$ & \\
\hline & & $y$ & $\searrow y$ & \\
\hline \multirow[t]{3}{*}{$\mathrm{H} 115$} & \multirow[t]{3}{*}{ relatively constant, can be used } & $\searrow y$ & $y$ & \multirow{3}{*}{$\begin{array}{l}\text { generally wrong, inverted trends, but on a } \\
\text { low error level }\end{array}$} \\
\hline & & $\searrow y$ & $y$ & \\
\hline & & $y$ & スス & \\
\hline \multirow[t]{3}{*}{ H118 (=W87) } & \multirow{3}{*}{$\begin{array}{l}\text { especially susceptible if shear and } \\
\text { compression combined, should be deleted } \\
\text { in this case (or scored '?') }\end{array}$} & ス & $\pi$ & \multirow{3}{*}{$\begin{array}{l}\text { bad performance if shear involved, MM } \\
\text { indicates trend if compression only }\end{array}$} \\
\hline & & $\searrow y$ & $y$ & \\
\hline & & $y$ & $y \geq$ & \\
\hline \multirow[t]{3}{*}{ U1 } & \multirow[t]{3}{*}{ susceptible, use with care } & スス & $\pi$ & \multirow{3}{*}{$\begin{array}{l}\text { bad performance if shear involved, MM } \\
\text { indicates trend if compression only }\end{array}$} \\
\hline & & $\searrow$ & $\searrow \searrow$ & \\
\hline & & $\searrow$ & $\searrow \searrow$ & \\
\hline
\end{tabular}

would not be possible to circumvent the exclusion of these characters. One possibility would be to apply the same methods as proposed here, including the Raphus cucullatus test, for all the taxa included in the phylogenetic analysis. By doing so, deformation of the vertebrae could be assessed taxon by taxon. To date, however, very few sauropod bones are available as 3D models. Therefore, taxa for which no retrodeformation data is available would have to be scored as unknown for this char- 
TABLE 3. Support values of the performed phylogenetic analyses with and without the questionable characters $(\mathrm{H} 112$, H114 for Harris, 2006; W90 for Whitlock, 2011). Abb.: MPT, most parsimonious tree.

\begin{tabular}{lccccc}
\multicolumn{2}{c}{ Phylogenetic analysis } & Tree length & Number of MPTs & Consistency index & Retention index \\
\hline Harris (2006) & with & 965 & 50 & 44 & 62 \\
& without & 899 & 6 & 47 & 66 \\
\cline { 2 - 6 } Whitlock (2011) & with & 354 & 1 & 70 & 83 \\
& without & 350 & 1 & 71
\end{tabular}

acter. In some cases this might result in characters scored for only one or two taxa, such that no additional phylogenetic value would be generated. Nonetheless, this will be a promising approach for the future. In the case of character H114 (or W90), a different approach was chosen by Tschopp and Mateus (in press). $\mathrm{H} 114$ describes the elongation of the vertebral centra. Their definitions of the states vary in the two analyses: Harris (2006) defines the states as "<4.0 (0); $\geq 4.0$ (1)," and Whitlock (2011) as "2.5-3 (0); $4+(1)$." In the case of
SMA 0004, both of these definitions appear to be problematic, because both the original elements as well as the MM-16 models fall in between the borders as set by Whitlock (2011) to distinguish diplodocine taxa from e.g., Apatosaurus. Since the Raphus cucullatus test indicates that MM-16 produced a reasonable model in this case (Table 1), the intermediate state of SMA 0004 between the short cervical vertebrae of Apatosaurus and the very elongated ones of the more derived diplodocines Diplodocus, Barosaurus, or Tornieria,

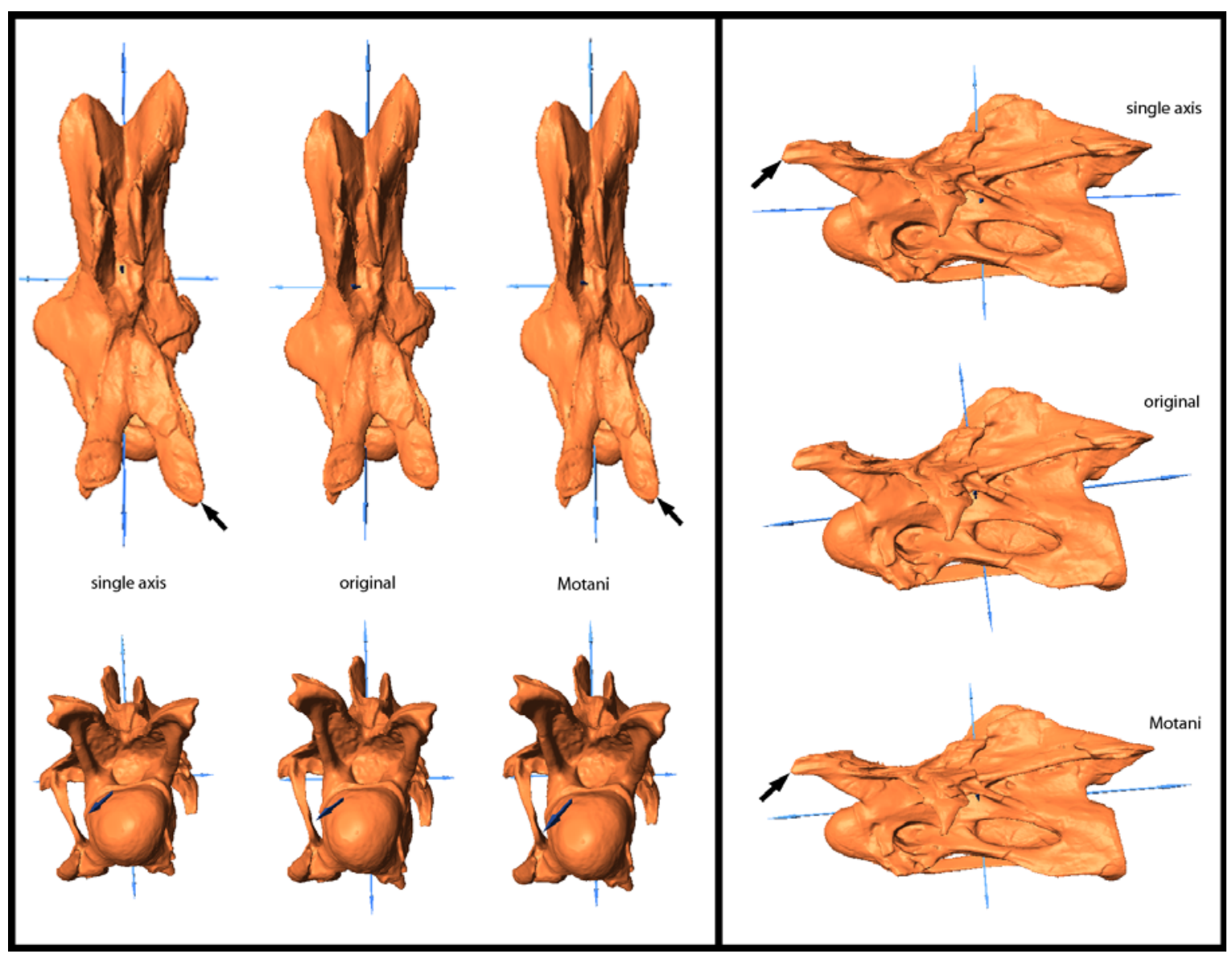

FIGURE 5. Original and retrodeformed models of CV 10 in dorsal (top left), anterior (bottom left), and lateral view (right). Note the elongation of the prezygapophysis in the retrodeformed models (arrow) and the slenderness of the model produced by the MM. Vertebrae not to scale. 


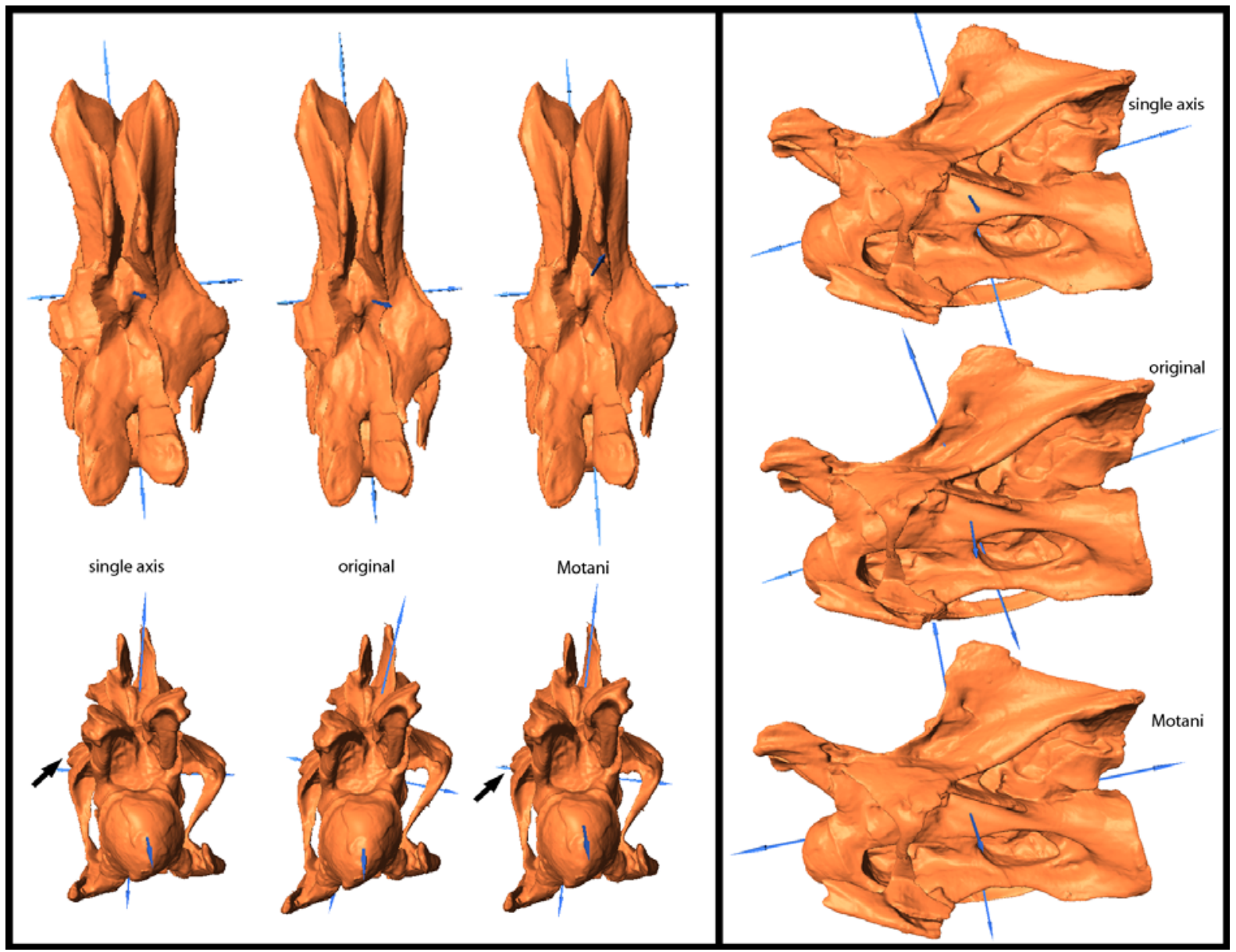

FIGURE 6. Original and retrodeformed models of CV 11 in dorsal (top left), anterior (bottom left), and lateral view (right). Note the levelling of the transverse processes in the retrodeformed models (arrows). Vertebrae not to scale.

appears taxonomically significant. Thus, if one would use Harris' (2006) definition, this intermediate state would not be resolved. Tschopp and Mateus (in press) therefore added an intermediate state to Whitlock's (2011) definition: $\leq 3$ (0); 3.1-3.9 (1); $\geq 4$ (2). This shows that retrodeformation - if tested simultaneously - can serve as a tool to validate phylogenetic characters and to modify them accordingly.

\section{CONCLUSIONS}

Although many different approaches were made to reconstruct deformed fossils automatically, many of them only consider two dimensions. When applying retrodeformation to 3D objects, it becomes obvious that shape can change considerably in all dimensions, affecting also ratios used for phylogenetic characters. Testing the used retrodeformation methods with manually deformed, mor- phologically similar elements, allows validation of trends recovered for the fossils under study, and helps to identify phylogenetic characters that are highly susceptible to deformation. In this case study, deletion of such questionable characters lead to better resolved trees with generally higher support values, which in turn confirms the usefulness of retrodeformation as tool for testing the validity of phylogenetic characters.

\section{ACKNOWLEDGMENTS}

We are very grateful to L. Jacobs, M. Polcyn, and R. Araújo (South. Methodist Univ., Dallas, Texas, USA) for giving access to high end 3D software and computers at the Visualization Lab of the Huffington Department of Earth Sciences, and for helpful comments on a first draft of the manuscript. $\mathrm{O}$. Mateus and C. Hendrickx reviewed an earlier version of this paper. H.-J. Siber (SMA) kindly 


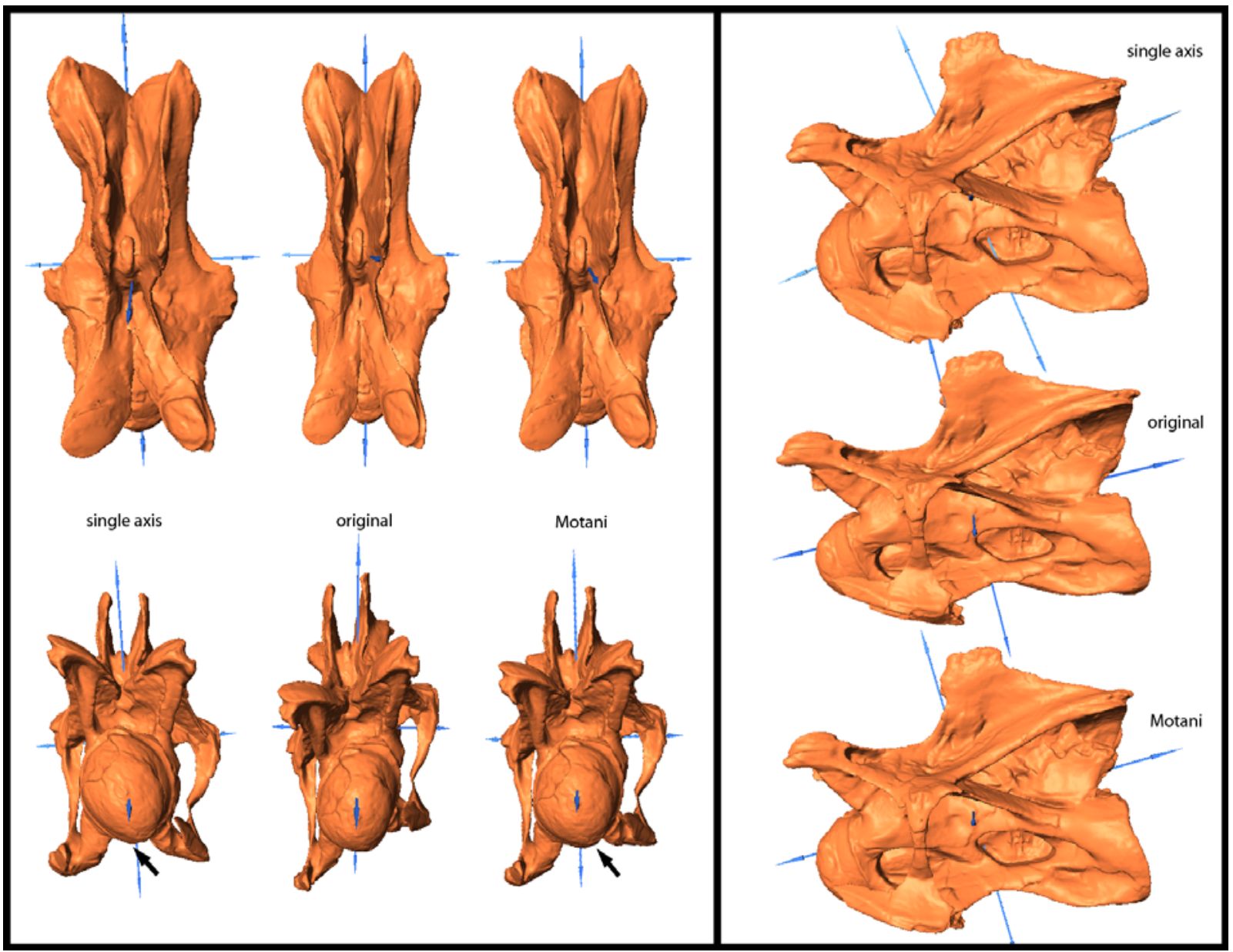

FIGURE 7. Original and retrodeformed models of CV 12 in dorsal (top left), anterior (bottom left), and lateral view (right). Note the more rounded condyles (arrows) and the pronounced robustness of the model produced by the SAM. Vertebrae not to scale.

allowed us to scan and analyze this valuable specimen. A. Christian, J.-T. Möller (Univ. of Flensburg, Germany), M. Kistler, and B. Pabst (SMA) helped with the dismantling and scanning of SMA 0004. We are deeply indebted to D. Allan (DNSM) and L. Claessens (Holy Cross, Worcester, USA) for providing the 3D model of the Dodo cervical. D. Wiley (Univ. of California) was providing references and further information concerning the retrodeformation tools. Last but not least, we thank two anonymous referees for their detailed and very helpful reviews.

E. Tschopp is supported by the Fundação para a Ciência e a Tecnologia doctoral fellowship SFRH / BD / 66209 / 2009 (Ministério da Ciência, Tecnologia e Ensino superior, Portugal), under which he also received additional travel subsidies for his stay at South. Methodist Univ.

\section{REFERENCES}

Angielczyk, K.D. and Sheets, H.D. 2007. Investigation of simulated tectonic deformation in fossils using geometric morphometrics. Paleobiology, 33:125-148.

Arbour, V.M. and Currie, P.J. 2012. Analyzing taphonomic deformation of ankylosaur skulls using retrodeformation and Finite Element Analysis. PLOS ONE 7:e39323. doi:10.1371/journal.pone.0039323.

Boyd, A.A. and Motani, R. 2008. Three-dimensional reevaluation of the deformation removal technique based on "jigsaw puzzling". Palaeontologia Electronica, 11:1-7.

Cooper, R.A. 1990. Interpretation of tectonically deformed fossils. New Zealand Journal of Geology and Geophysics, 33:321-332.

Dunlavey, T., Mitchell, C., and Sheets, H.D. 2004. Retrodeformation is paramount to the accurate description of fossil taxa. Geological Society of America Abstracts with Programs, 36:422. 


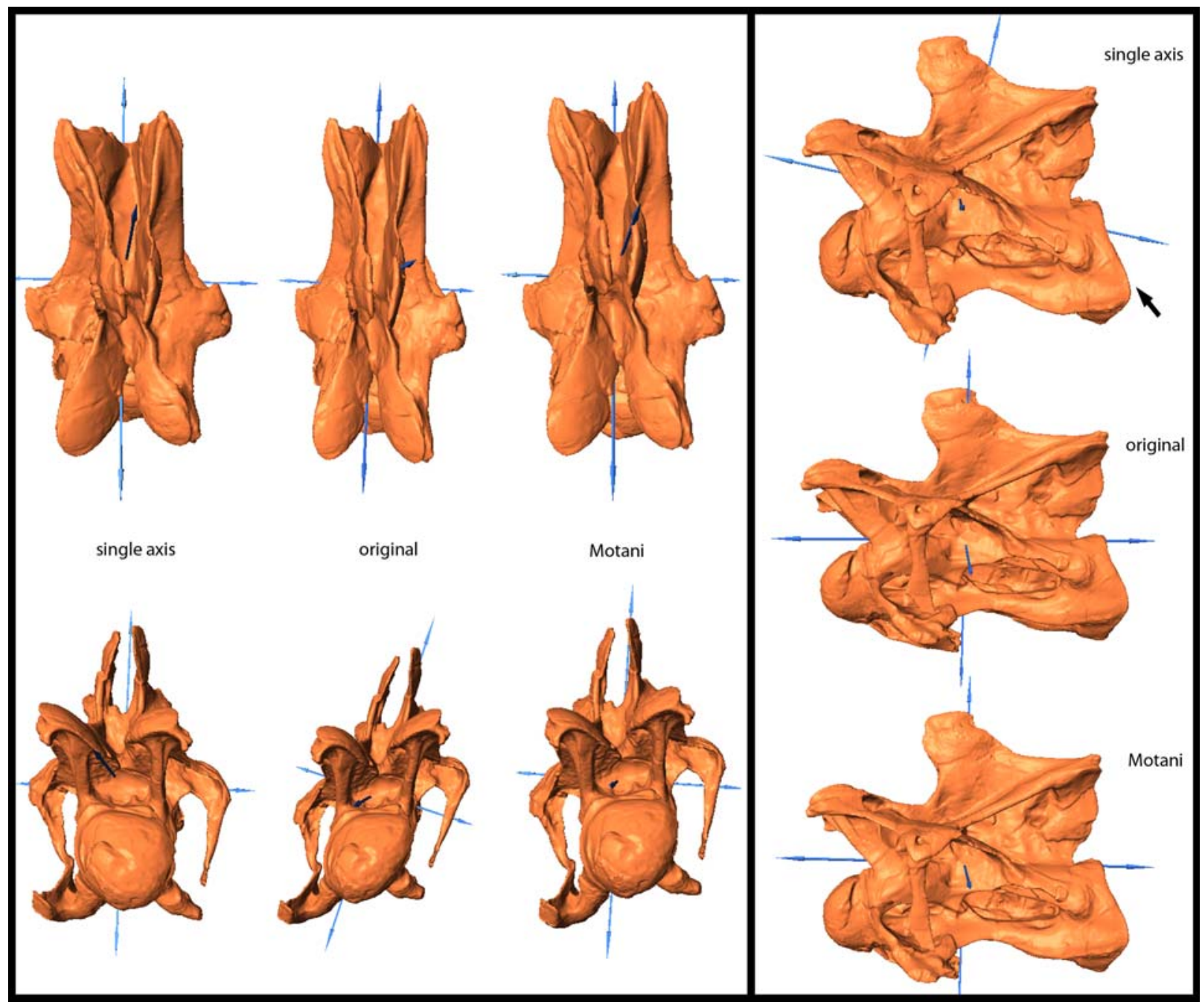

FIGURE 8. Original and retrodeformed models of CV 13 in dorsal (top left), anterior (bottom left), and lateral view (right). Note the more pronounced posteroventral corner in the SAM (arrow). Vertebrae not to scale.

Gunz, P., Mitteroecker, P., Neubauer, S., Weber, G.W., and Bookstein, F.L. 2009. Principles for the virtual reconstruction of hominin crania. Journal of Human Evolution, 57:48-62.

Harris, J.D. 2006. The significance of Suuwassea emilieae (Dinosauria: Sauropoda) for flagellicaudatan intrarelationships and evolution. Journal of Systematic Palaeontology, 4:185-198.

Hughes, N.C. and Jell, P.A. 1992. A statistical/computergraphic technique for assessing variation in tectonically deformed fossils and its application to Cambrian trilobites from Kashmir. Lethaia, 25:317-330.

Kazhdan, M., Amenta, N., Gu, S., Wiley, D.F., and Hamann, B. 2009. Symmetry restoration by stretching. Canadian Conference on Computational Geometry, Vancouver, p. 4.
Linnaeus, C. 1758. Systema naturae per regna tria naturae: secundum classes, ordines, genera, species, cum characteribus, differentiis, synonymis, locis. Impensis Direct, Laurentii Salvii, Stockholm, Sweden. 911 pages, doi: http://dx.doi.org/10.5962/bhl.title.542

Molnar, J.L., Pierce, S.E., Clack, J.A., and Hutchinson, J.R. 2012. Idealized landmark-based geometric reconstructions of poorly preserved fossil material: a case study of an early tetrapod vertebra. Palaeontologia Electronica, 15.1.2T, $18 \mathrm{p}$.

Motani, R. 1997. New technique for retrodeforming tectonically deformed fossils, with an example for ichthyosaurian specimens. Lethaia, 30:221-228.

Motani, R., Amenta, N., and Wiley, D.F. 2005. Possibilities and limitations of three dimensional retrodeformation of a trilobite and plesiosaur vertebrae. PaleoBios, 25:88. 


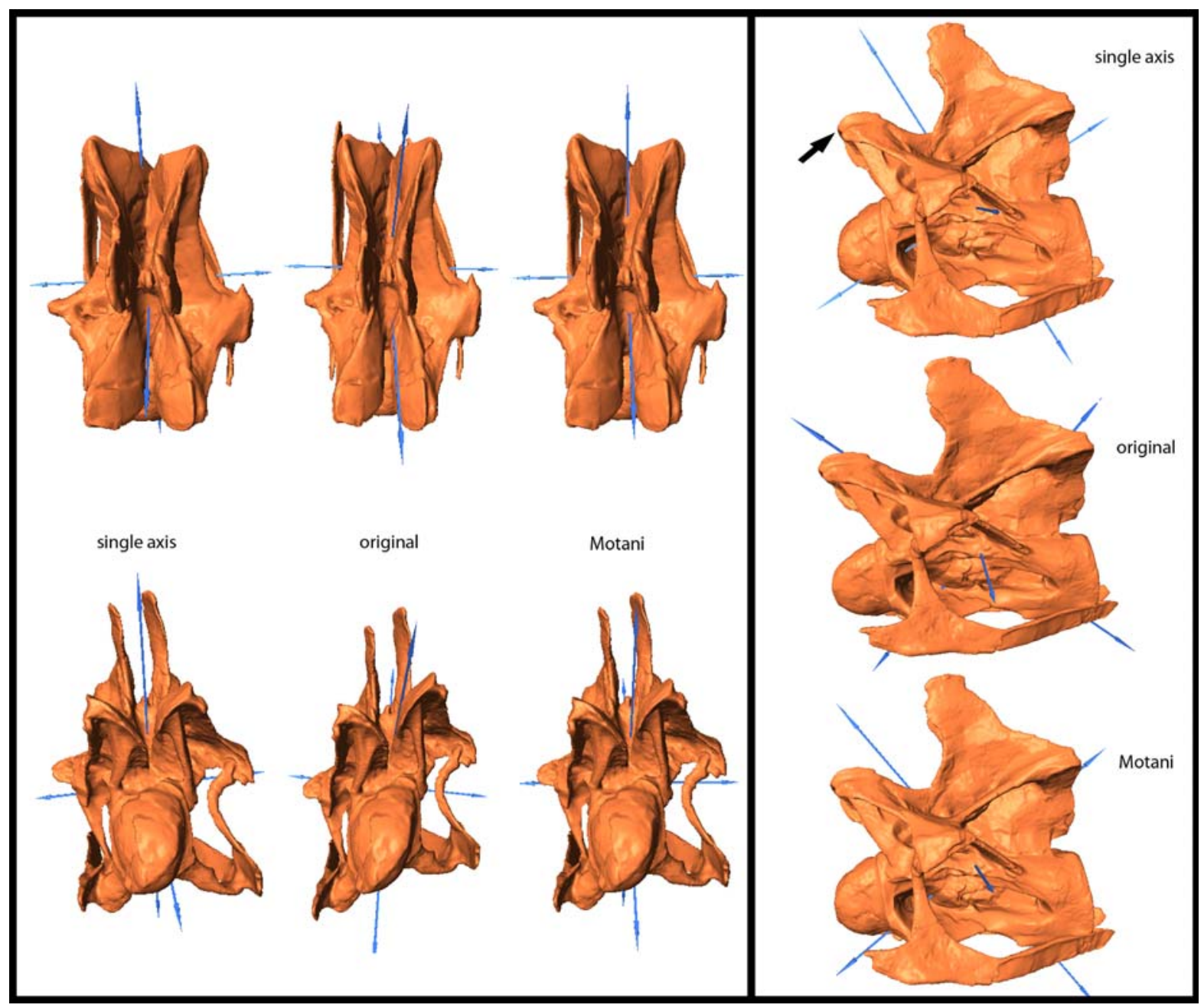

FIGURE 9. Original and retrodeformed models of CV 14 in dorsal (top left), anterior (bottom left), and lateral view (right). Note the retraction of the prezygapophyses in the retrodeformed models (arrows) and the robustness of the model produced by the SAM. Vertebrae not to scale.

Ogihara, N., Nakatsukasa, M., Nakano, Y., and Ishida, H. 2006. Computerized restoration of nonhomogeneous deformation of a fossil cranium based on bilateral symmetry. American Journal of Physical Anthropology, 130:1-9. doi:10.1002/ajpa.20332.

Polcyn, M.J., Jacobs, L.L., and Haber, A. 2005. A morphological model and CT assessment of the skull of Pachyrhachis problematicus (Squamata, Serpentes), a 98 million year old snake with legs from the Middle East. Palaeontologia Electronica, 8 (1):1-24. http:// palaeo-electronica.org/paleo/2005_1/polcyn26/ issue1_05.htm

Ponce de León, M.S. and Zollikofer, C.P.E. 1999. New evidence from Le Moustier 1: Computer-assisted reconstruction and morphometry of the skull. The Anatomical Record, 254:474-489.
Rushton, A.W.A. and Smith, M. 1993. Retrodeformation of fossils-a simple technique. Palaeontology, 36:927930.

Sdzuy, K. 1966. An improved method of analyzing distortion in fossils. Palaeontology, 9:125-134.

Srivastava, D.C. and Shah, J. 2006. Digital method for strain estimation and retrodeformation of bilaterally symmetric fossils. Geology, 34:593-596.

Tschopp, E. and Dzemski, G. 2012. 3-dimensional reproduction techniques to preserve and spread paleontological material - a case study with a diplodocid sauropod neck. Journal of Paleontological Techniques, 10:1-8.

Tschopp, E. and Mateus, O. In press. The skull and neck of a new diplodocid sauropod from the Morrison Formation and the evolution of flagellicaudatan dinosaurs. Journal of Systematic Palaeontology. doi: 10.1080/14772019.2012.746589 


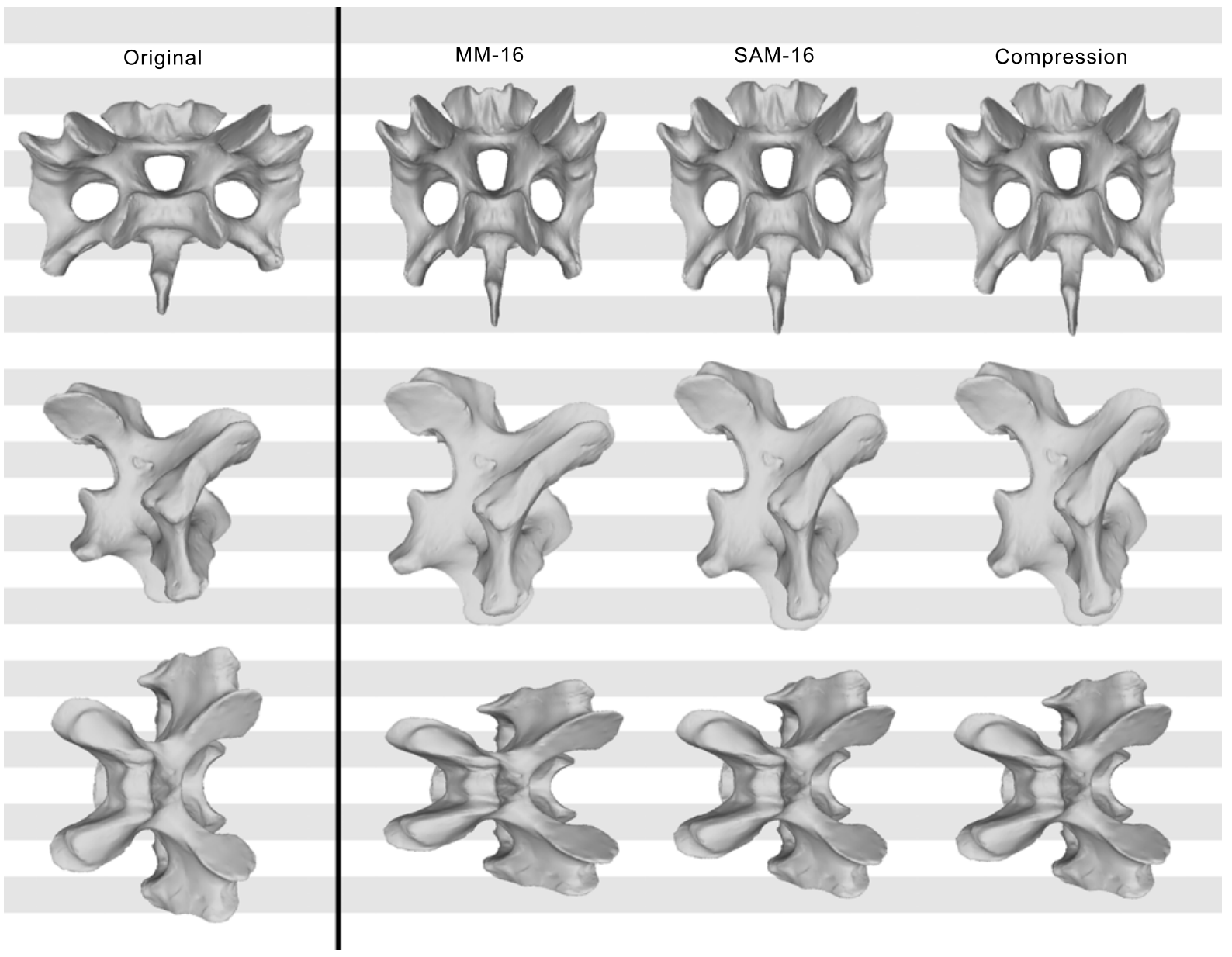

FIGURE 10. Original, deformed (using compression), and retrodeformed models of a cervical vertebra of Raphus cucullatus (DNSM Ornithology 2366) in anterior (top), right lateral (center), and dorsal (bottom) view. Note the transversely more compressed retrodeformed models compared to the deformed model.

Upchurch, P., Tomida, Y., and Barrett, P.M. 2004. A new specimen of Apatosaurus ajax (Sauropoda: Diplodocidae) from the Morrison Formation (Upper Jurassic) of Wyoming, USA. National Science Museum Monographs, 26:1-108.

Whitlock, J.A. 2011. A phylogenetic analysis of Diplodocoidea (Saurischia: Sauropoda). Zoological Journal of the Linnean Society, 161:872-915. doi:10.1111/ j.1096-3642.2010.00665.x.

Wiley, D.F., Amenta, N., Alcantara, D.A., Ghosh, D., Kil, Y.J., Delson, E., Harcourt-Smith, W., Rohlf, F.J., St John, K., and Hamann, B. 2005. Evolutionary morphing. Visualization, 2005. VIS 05. IEEE, p. 431-438.

Williams, S.H. 1990. Computer-assisted graptolite studies, p. 46-55. In Bruton, D.L. and Harper, D.A.T. (eds.), Microcomputers in Palaeontology. Contributions from the Palaeontology Museum, University of Oslo. Oslo.

Wilson, J.A. 1999. A nomenclature for vertebral laminae in sauropods and other saurischian dinosaurs. Journal of Vertebrate Paleontology, 19:639-653.
Wilson, J.A. 2002. Sauropod dinosaur phylogeny: critique and cladistic analysis. Zoological Journal of the Linnean Society, 136:215-275.

Zollikofer, C.P.E. and Ponce De León, M.S. 2005. Virtual Reconstruction: A primer in Computer-assisted Paleontology and Biomedicine. Wiley-Interscience, Hoboken, NJ.

Zollikofer, C.P.E., Ponce de León, M.S., and Martin, R.D. 1998. Computer-assisted paleoanthropology. Evolutionary Anthropology: Issues, News, and Reviews, 6:41-54

Zollikofer, C.P.E., Ponce de León, M.S., Chaimanee, Y., Lebrun, R., Tafforeau, P., Khansubhaand, S., and Jaeger, J.-J. 2009. The face of Siamopithecus: new geometric-morphometric evidence for its anthropoid status. The Anatomical Record: Advances in Integrative Anatomy and Evolutionary Biology, 292:17341744. doi:10.1002/ar.20998.

Zollikofer, C.P.E., Ponce de León, M.S., Lieberman, D.E., Guy, F., Pilbeam, D., Likius, A., Mackaye, H.T., Vignaud, P., and Brunet, M. 2005. Virtual cranial reconstruction of Sahelanthropus tchadensis. Nature, 434:755-759. 
TSCHOPP, RUSSO, \& DZEMSKI: RETRODEFORMATION AND PHYLOGENY

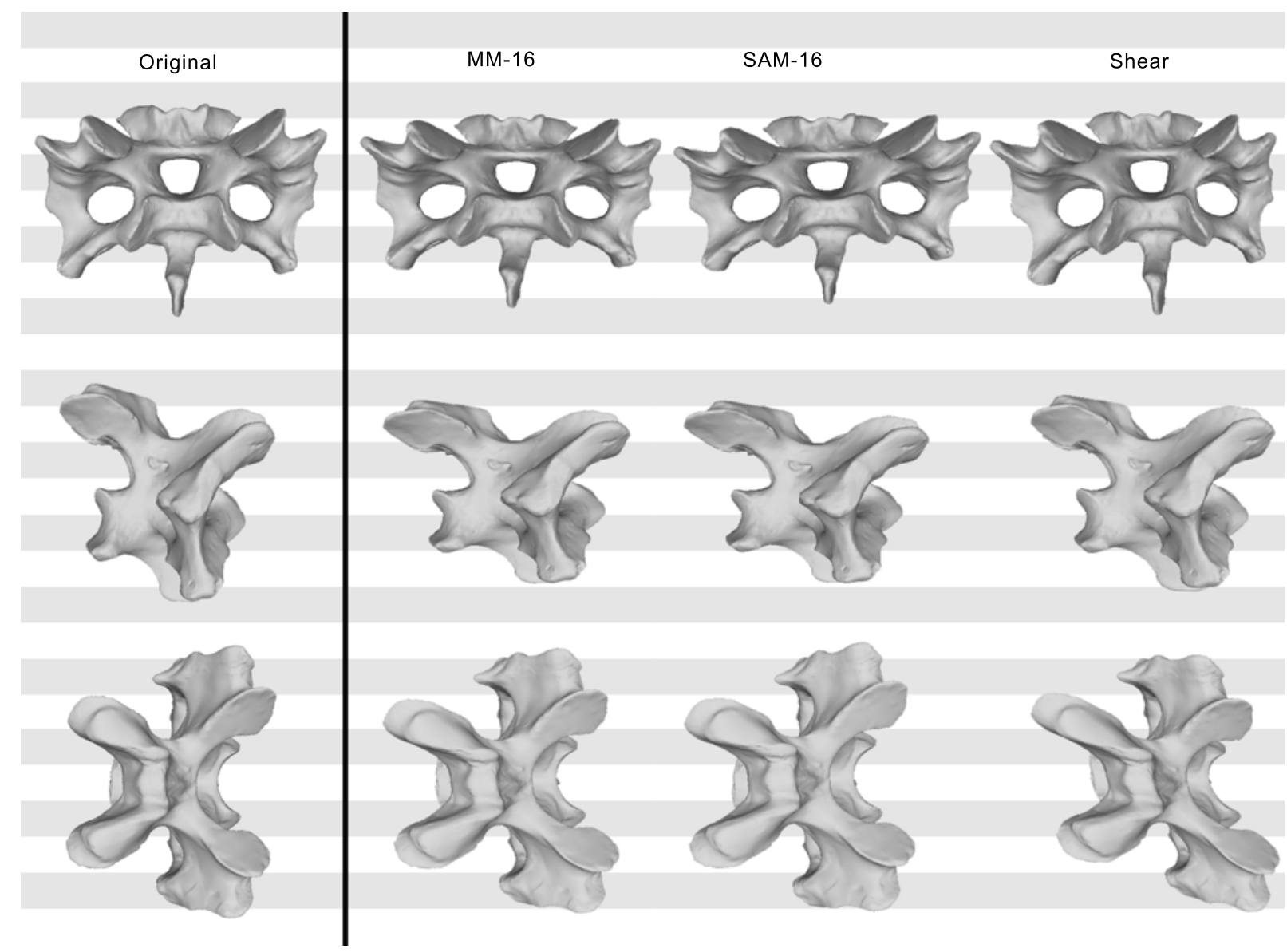

FIGURE 11. Original, deformed (using shear), and retrodeformed models of a cervical vertebra of Raphus cucullatus (DNSM Ornithology 2366) in anterior (top), right lateral (center), and dorsal (bottom) view. Note the dorsoventrally more compressed retrodeformed models compared to the deformed model. 


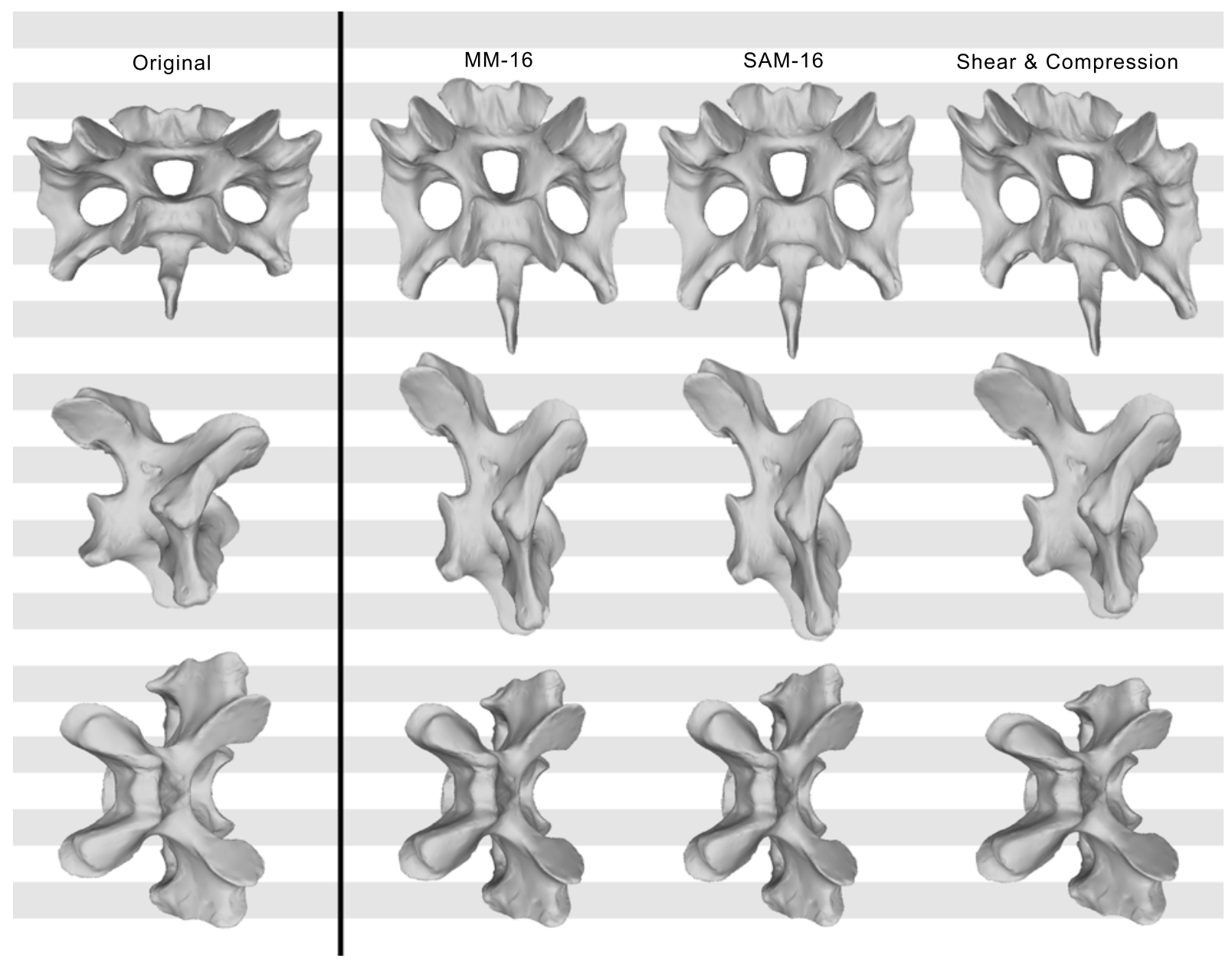

FIGURE 12. Original, deformed (compression and shear combined), and retrodeformed models of a cervical vertebra of Raphus cucullatus (DNSM Ornithology 2366) in anterior (top), right lateral (center), and dorsal (bottom) view. Note the dorsoventrally higher, and anteroposteriorly shorter retrodeformed models compared to the deformed model. 


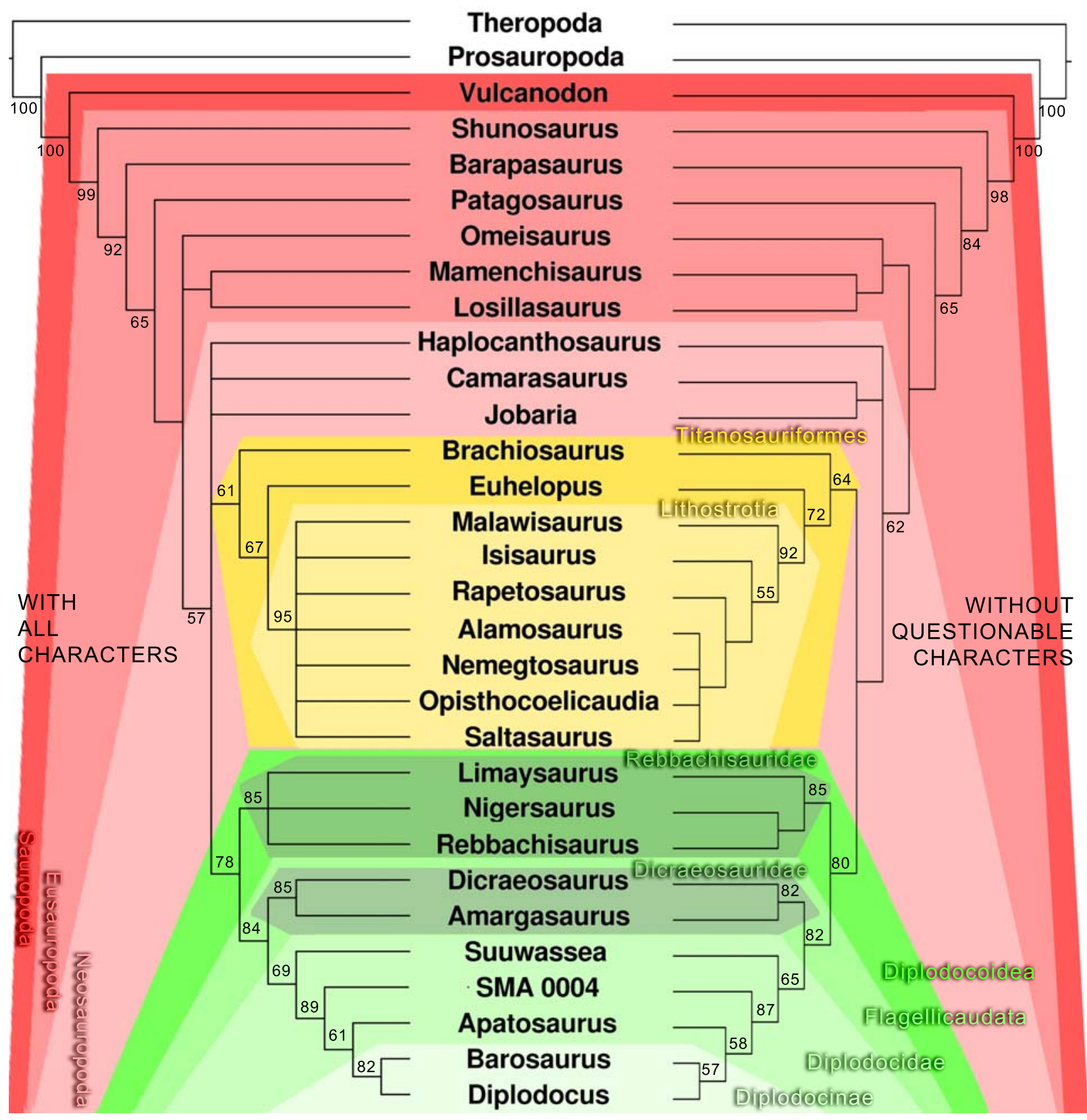

FIGURE 13. Phylogenetic trees (based on Harris, 2006) recovered with (left) and without (right) the questionable characters $(\mathrm{H} 112$ and H114). Bootstrap values indicated if $>50$. Note the better resolved tree without the questionable characters. Bootstrap values in the right tree are higher for high-level, but lower for low-level taxa. 


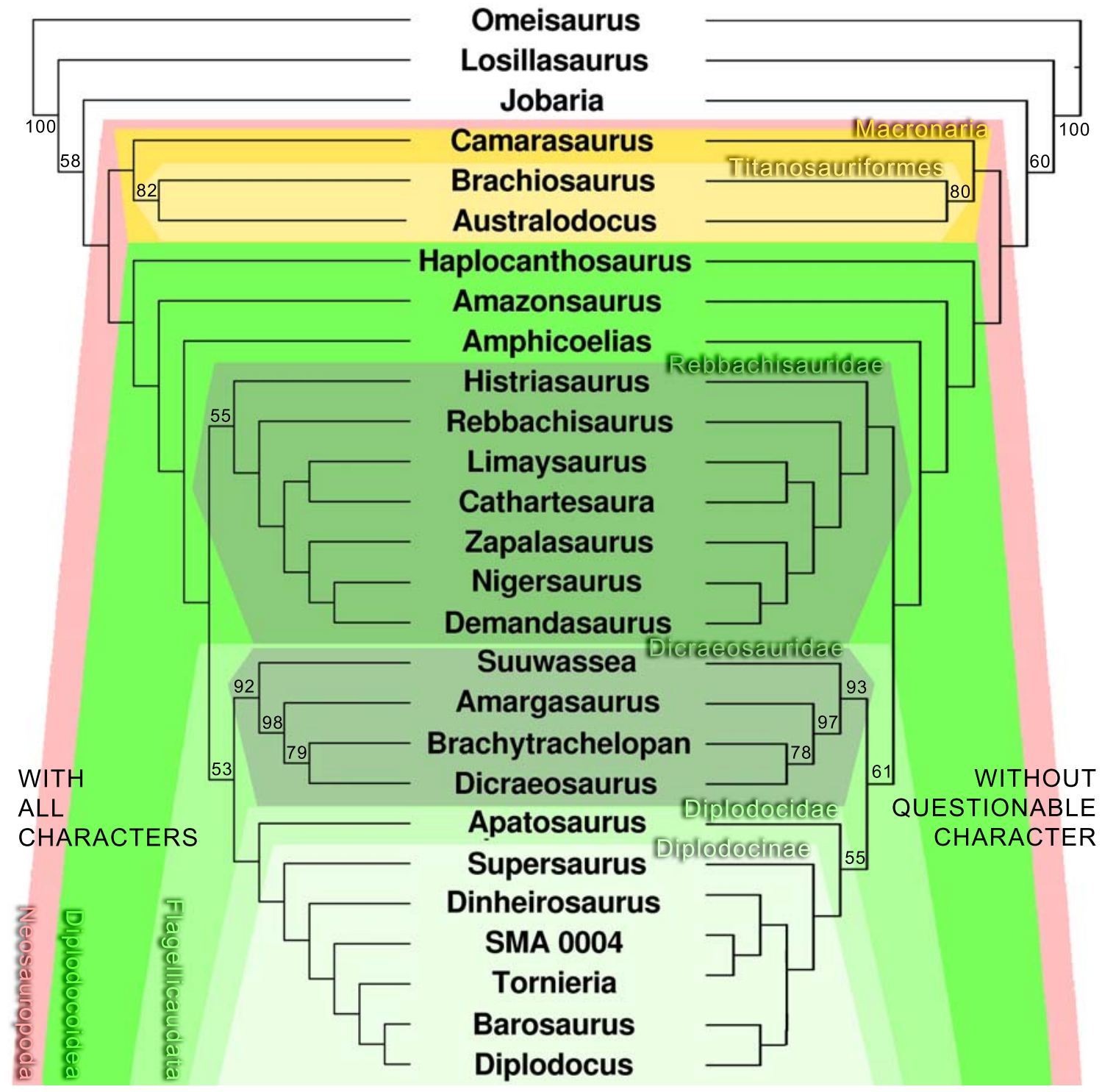

FIGURE 14. Phylogenetic trees (based on Whitlock, 2011) recovered with (left) and without (right) the questionable character (W90). Bootstrap values indicated if $>50$. Note the differences in diplodocine intrarelationships. Bootstrap values in the right tree are higher for high-level, but lower for low-level taxa. 


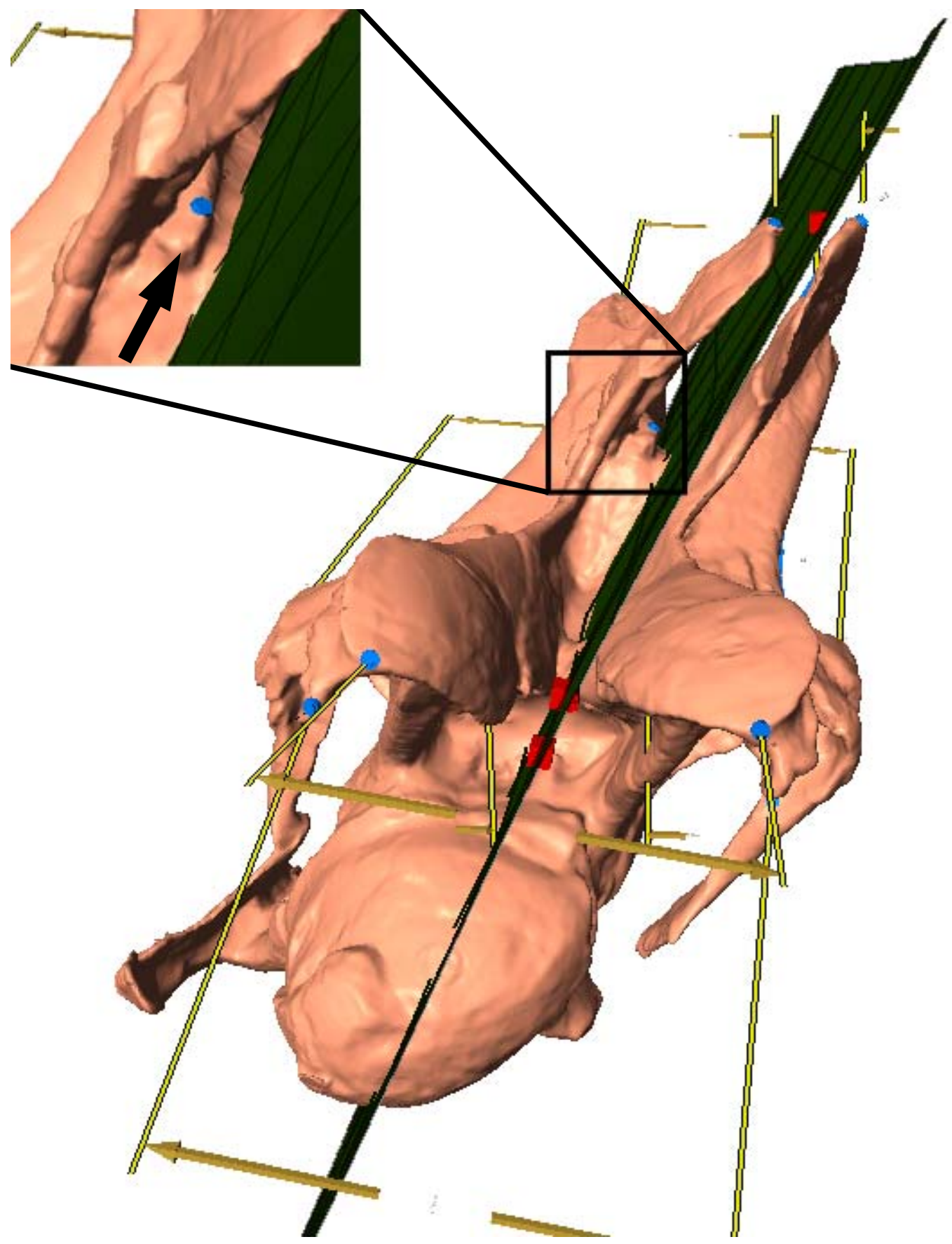

FIGURE 15. Calculated midsagittal plane on original model of CV 13 in oblique anterodorsal view. The used symmetrical pairs of landmarks are indicated in yellow and blue, the midsagittal plane in green. Note the medial tuberosity (arrow in close-up), which is supposed to lie on the midsagittal plane, but the methods used herein do not allow to include single points. 


\section{SUPPLEMENTARY MATERIAL}

APPENDIX 1. Video of CV 14 in lateral view. Sequence runs from the digital model of the original fossil to the SAM, $\mathrm{MM}$, and back to the original model.

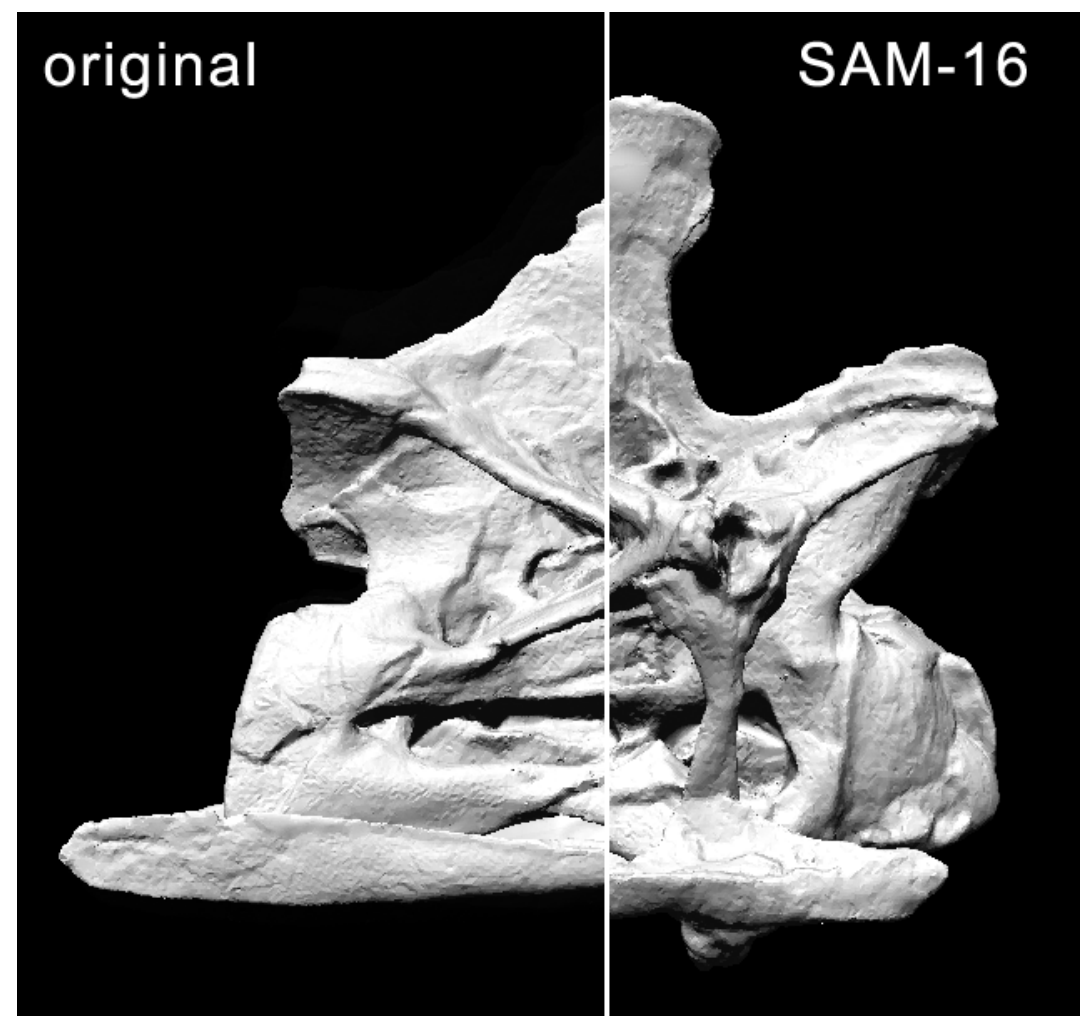


APPENDIX 2. Video of CV 14 in dorsal view. Sequence runs from the digital model of the original fossil to the SAM, $\mathrm{MM}$, and back to the original model.

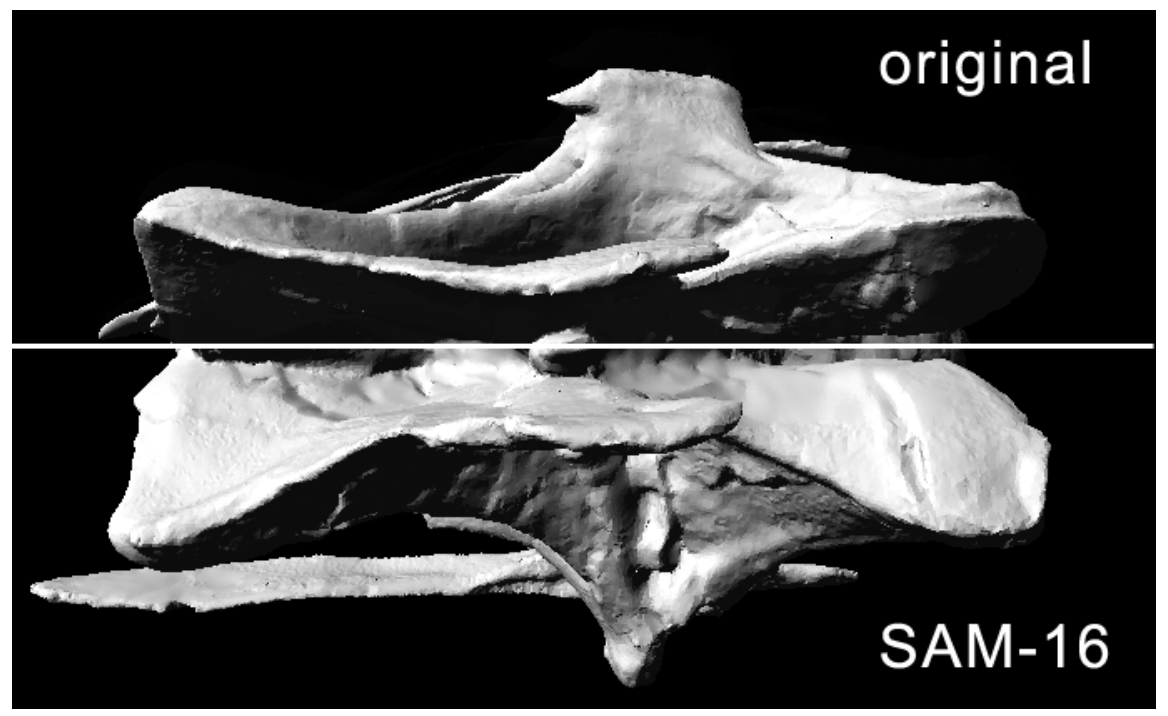


APPENDIX 3. Video of CV 14 in posterior view. Sequence runs from the digital model of the original fossil to the SAM, $\mathrm{MM}$, and back to the original model.

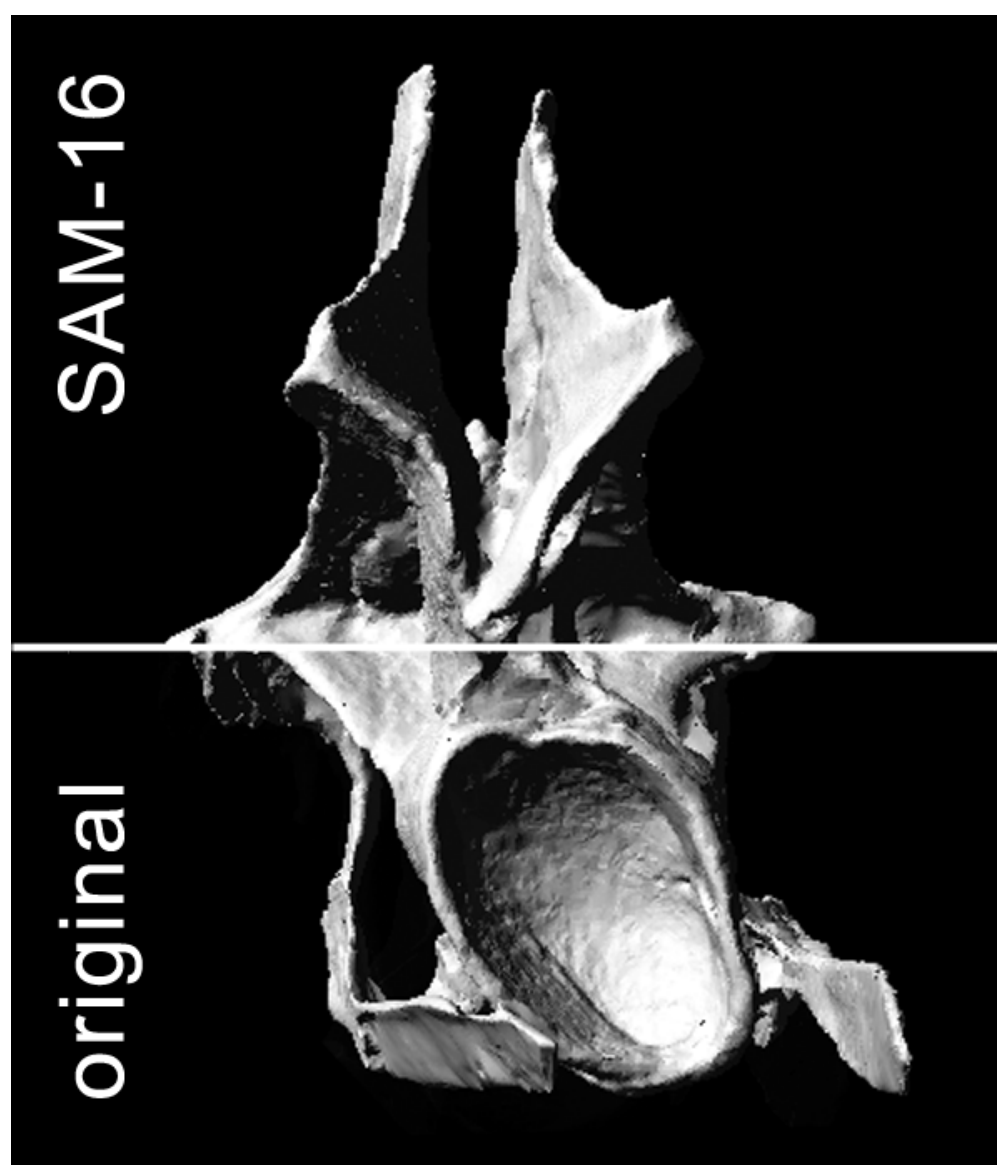

